\title{
Biochemical Development of Surface Activity in Mammalian Lung. IV. Pulmonary Lecithin Synthesis in the Human Fetus and Newborn and Etiology of the Respiratory Distress Syndrome
}

\author{
Louis Gluck ${ }^{[39]}$, Marie V. Kulovich, Arthur I. Eidelman, Leandro Cordero, and Aida F. Khazin \\ Department of Pediatrics, University of California, San Diego, School of Medicine, La Jolla, California, USA
}

\section{Extract}

The surface-active complex lining alveoli in normal lung lowers surface tension on expiration, thus preventing alveolar collapse. Surface activity follows a developmental timetable. Infants with idiopathic respiratory distress syndrome (RDS) almost exclusively are prematurely born, and their lungs lack adequate surface activity and are deficient in the principal surface-active component, lecithin. This deficiency implies that RDS is a "disease of development," with fetal and neonatal timetables for lecithin synthesis. The biosynthesis of lung lecithin in the living human infant was studied by examining phospholipids in lung effluent (pharyngeal aspirates, mucus), which have identical phospholipids to those in lung lavage (alveolar wash). The fatty acid esters of isolated lecithin and phosphatidyl dimethylethanolamine (PDME) were examined. The $\beta$-carbon fatty acids are indicators of the primary pathways of synthesis of lecithin: (1) a preponderance of palmitic acid signifying cytidine diphosphate choline (CDP-choline) + $D-\alpha, \beta$-diglyceride $\rightarrow$ lecithin (choline incorporation pathway) and (2) a preponderance of myristic acid signifying phosphatidyl ethanolamine $(\mathrm{PE})+2 \mathrm{CH}_{3} \rightarrow P D M E+$ $\mathrm{CH}_{3} \rightarrow$ lecithin (methylation pathway).

Fetal lung of 18 and 20 weeks showed slight incorporation by GDP-choline pathway, absence of PDME, and almost no methylation. Salivary lecithin had totally different fatty acids from lecithin in aspirates. Phosphatidyl dimethylethanolamine (PDME) (therefore methylation) was identified in aspirates as early as 22--24 week-gestation. Lecithin fatty acid esters in aspirates from premature infants after birth or those with no RDS closely resembled PDME fatty acids. With RDS, PDME disappears and $\beta$-carbon palmitic acid (therefore dipalmitoyl lecithin) increases. With recovery, PDME reappears, as does the premature infant's major lecithin, palmitoylmyristoyl. Full term infants are born with more $\beta$-carbon palmitic acid $(20-40 \%)$ and by $12-18$ hr have equal palmitic and myristic acids, indicating function of both lecithin synthesis pathways. Stress (hypoxia acidosis, hypothermia) cause disappearance of PDME and loss of $\beta$-carbon myristic acid. Similar changes in full term infants who do 
not get RDS are due to adequate lecithin synthesis by the GDP-choline pathway. The capacity to synthesize lecithin in the lung by methylation in the human fetus and newborn allows the human to be born prematurely; rabbits and sheep lack this capacity and cannot be prematures, but die from respiratory insufficiency if born too soon.

\section{Speculation}

The diagnosis of RDS can be made objectively by looking for PDME in aspirates (lung effluent). Prognosis also can be established by lack or presence of PDME. The effects of various therapies also can be assessed this way. The techniques and consideration described herein can be employed to study biochemically the effects of other stresses to lung, including oxygen toxicity and anesthesia.

\section{Introduction}

Surface activity of lung follows a developmental timetable and first is detected in late fetal life [2, 6, 9, $17-20,24,28,30,31]$. In normal lung, alveoli are lined with a surface-active complex containing the phospholipid lecithin, its principal component. The lining stabilizes alveoli by lowering surface tension on expiration, thus preventing alveolar collapse, but is lacking in lungs from infants dying of the idiopathic respiratory distress syndrome (RDS) $[3,6,23]$.

RDS is characterized by progressive atelectasis (with consequent widespread anoxic changes) of lungs of premature infants. Lungs from infants dying with RDS are unstable, collapse at low volumes, are difficult to inflate with air, do not exhibit normal lowered tension of saline extracts on surface compression in a modified Wilhelmy balance [6], and have significantly less than normal lecithin $[3,8,11]$.

Because RDS affects prematurely born infants almost exclusively and surface activity is a phenomenon of fetal development, RDS has implications as a disease of development. Surface activity development in fetal and newborn rabbit lung depends upon biosynthesis of lecithin in lung during fetal maturation and after the onset of breathing [17-20,28]. Similar information about biosynthesis of lecithin in developing human lung is essential to understand, biochemically, both normal respiratory adjustment of the newborn and the pathogenesis of RDS.

There are no known published studies about biosynthesis of lecithin in human lung. Investigations of human pulmonary phospholipids were conducted at autopsy on lungs from infants with and without RDS, including surface activity $[3,6,8,11,23]$, quantitative estimations [3, 8, 11], and acyl esters of lecithin [8]. Necessarily, these studies were static owing to the im- possibilities of studying living humans with techniques used on laboratory animals.

A series of observations suggested a way to study the biosynthesis of surface-active alveolar wash phospholipids in living human infants. First, it has been established that the fluid distending fetal lung is produced by the lung and is not amniotic fluid [17]. Measured flow rates (e.g., sheep) show that this fluid issues from lung into the nasopharynx [1] at rates as high as $30-120 \mathrm{ml} / \mathrm{hr}$ [34]. These secretions continue after birth. Second, there was close correspondence between the component lipids in the newborn infant's lung secretions and those in alveolar wash from lungs of infants who died (described in this report). Furthermore, in newly born rabbits, radioactive lecithin appeared rapidly in tracheal aspirates after intraperitoneal injection of radioactive precursors. [20]. Third, it was established in rabbits (and sheep) that the acyl ester structure of surface-active lecithin synthesized by each of the two major pathways for synthesis of lecithin in lung is distinct. That produced by incorporation of cytidine diphosphate choline (CDP-choline) + $D-\alpha, \beta$-diglyceride predominantly was $\alpha$-palmitic/ $\beta$ palmitic acid [18], whereas acyl ester composition of surface-active lecithin, synthesized by methylation of phosphatidyl ethanolamine, was found to be largely $\alpha$-palmitic/ $\beta$-myristic acid [18].

Thus, a qualitative estimation of each pathway for de novo biosynthesis of lecithin could be made from the fatty acids esterified on the $\beta$-carbons. This estimation could be done in the living infant by examining the lecithin in the tracheal effluent (tracheal aspirates).

This is a report of the phospholipids in lung secretions, recovered as tracheal or oropharyngeal aspirates, or both, from full term and prematurely born human infants, both clinically normal and those with RDS. 
These studies were correlated when possible with findings on alveolar wash of lungs of infants who died. The investigations suggest that human fetal lung before term synthesizes its relatively small amount of surface-active lecithin by both pathways. Before 35-37 weeks of gestation, the methylation pathway seems essential to survival, and after 35-37 weeks the more important CDP-choline pathway becomes mature. The findings further suggest that loss of normal surface activity and resultant RDS in the prematurely born infant may follow compromise of the methylation pathway by abnormal physiologic states such as acidosis and hypothermia.

\section{Materials and Methods}

A total of 296 premature (130 with RDS and 166 normal) and 144 full term infants were studied [35] from Yale-New Haven Hospital and Hospital of St. Raphael, New Haven, Connecticut; Jackson Memorial Hospital, Miami, Florida; and University Hospital, San Diego, California. Premature infants were appropriately sized for short gestation; infants small for gestation and infants of mothers with diabetes mellitus represent abnormal metabolic states and will be included in subsequent reports.

On the first 35 infants, effluents of lung (tracheal aspirates) were collected endotracheally under direct laryngoscopy. These samples were identical to those obtained by posterior oropharyngeal suction with a bulb syringe or DeLee trap in the same infants, and all subsequent collections were aspirated from the oropharynx. Aspirates collected in sterile tubes either were extracted immediately or were stored at $-20^{\circ}$ until analyzed. On 150 infants, first specimens were obtained in the delivery room. Specimens were collected hourly from infants as long as they were not fed by mouth. In infants with RDS, specimens were collected hourly as long as RDS persisted, and for one or more collections after recovery. Each sample was as large as possible. The samples were frequently small and, when this occurred, several samples collected within a relatively short period were pooled to provide enough material for analysis.

From twenty-one of thirty-eight study infants who died, one or more lobes of lung were analyzed for phospholipids in alveolar wash. The wash was obtained as in previous descriptions [19], by gentle endobronchial lavage with $0.9 \%$ saline, and was centrifuged to remove cells and debris. Alveolar wash lipids $[19,20]$, were extracted with an equal volume of meth- anol and 2 volumes of chloroform. Lipids were then separated on microcolumns of diethylaminoethyl cellulose acetate (DEAE-acetate) and thin layer chromatography (TLC).

Lipids were extracted from aspirates as follows: each aspirate was emulsified (Vortex spinner) in $1 \mathrm{ml} 0.9 \%$ saline, $1 \mathrm{ml}$ absolute methanol added with mixing, and $1 \mathrm{ml}$ chloroform. Lipids were drawn off in the lower chloroform layer and were concentrated under nitrogen.

Nonacidic phospholipids (sphingomyelin, lecithin, phosphatidyl ethanolamine (PE), phosphatidyl methylethanolamine (PME), and phosphatidyl dimethylethanolamine (PDME)) were separated from the total lipid extract on microcolumns of $N, N$-diethylaminoethyl cellulose acetate $[16,36]$. Individual phospholipids were isolated by preparative TLC on silica gel H [16] (A.G. Merck, Darmstadt, Germany). Phospholipids from extracts too small for columns were isolated directly by TLC on silica gel $\mathrm{H}$.

Phospholipids were quantified by densitometry [16] or estimated from phosphorus content [7]. Lecithins were separated into acetone-soluble (non-surface active) and acetone-precipitated (surface-active) fractions $[19,20]$. (As noted previously $[19,20]$, concentration of the surface-active fraction with acetone is artificial but is the best way to measure changes in this physiologically active fraction. When small amounts are present in total lecithin, this may be the only way to detect any surface-active material. Surface activity is a unique property of saline extract of minced mammalian lung (and certain purified phospholipids) measured by surface compression and expansion in a modified Wilhelmy balance. When active, surface tensions range from below $10 \mathrm{dyn} / \mathrm{cm}$ on compression to above 30 dyn $/ \mathrm{cm}$ on expansion. The smallest amount of pure synthetic dipalmitoyl lecithin necessary (on $60-\mathrm{cm}^{2}$ surface) to demonstrate activity was $20 \mu \mathrm{g}$ [15]; purified acetone-precipitated lecithin from lung demonstrated identical surface activity with $20-25 \mu \mathrm{g}$ [19].)

Phospholipid fatty acid esters were analized after splitting $\beta$-carbon esters with phospholipase A ( Naja naja venom) [18], and $\alpha^{-}$and $\beta$-carbon fatty acids of lecithin and PDME were methylated separately. Gasliquid chromatography (GLC) conditions for fatty acids were as described previously [18], using glass columns of $15 \%$ diethylene glycol succinate on acidwashed silanized Chromosorb W. Isothermal column temperature was $180^{\circ}$, injector temperature was $290^{\circ}$, flame ionization detector temperature was $210^{\circ}$, and helium carrier gas pressure was $40 \mathrm{psi}$. 
Table I. Comparison of concentrations in lung of total phospholipids and of lecithin from 10 infants dying of nonpulmonary causes and 10 infants dying with hyaline membrane disease (HMD)

\begin{tabular}{lcc}
\hline & $\begin{array}{c}\text { Control } \\
\text { infants }\end{array}$ & $\begin{array}{c}\text { Infants dying } \\
\text { with HMD }\end{array}$ \\
\hline $\begin{array}{l}\text { Birth wt, kg } \\
\text { Mean }\end{array}$ & 1.7 & 1.6 \\
$\quad$ Range & $0.9-3.23$ & $0.9-3.15$ \\
$\begin{array}{l}\text { Age at death, days } \\
\text { Mean }\end{array}$ & 3.2 & 1.5 \\
$\quad \begin{array}{l}\text { Range } \\
\text { Total phospholipids, } \\
\quad \text { mg/g wet wt lung } \pm \mathrm{sD}\end{array}$ & $0.0-22.0$ & $0.5-5.0$ \\
$\begin{array}{l}\text { Total lecithin, } \\
\quad \text { mig/g wet wt lung } \pm \mathrm{SD}\end{array}$ & $10.3 \pm 2.1$ & $9.5 \pm 1.8$ \\
$\begin{array}{l}\text { Mininum surface tension } \\
\text { of saline extracts of } \\
\text { lung, dynes/cm }\end{array}$ & & $1.3 \pm 0.5$ \\
$\quad \begin{array}{l}\text { Mean } \\
\text { Range }\end{array}$ & & \\
\hline
\end{tabular}

1 On modified Wilhelmy balance.

Table II. In vitro incorporation into lecithin of radioactive precursors of de novo biosynthesis by homogenates of lung from two previable human fetuses whose lung wash contained no PDME'

\begin{tabular}{lcc}
\hline Radioactive precursor & \multicolumn{2}{c}{$\begin{array}{c}\text { Lecithin per mg homogenate } \\
\text { protein, net cpm }\end{array}$} \\
\cline { 2 - 3 } & $\begin{array}{c}\text { 18-week } \\
\text { fetal lung }\end{array}$ & $\begin{array}{c}20 \text {-week } \\
\text { fetal lung }\end{array}$ \\
\hline $\mathrm{CDP}-\left(1,2-{ }^{14} \mathrm{C}\right)$ choline & 438 & 317 \\
$\left({ }^{14} \mathrm{CH}_{3}\right)-S$-adenosyl-L-methionine & 32 & 11 \\
\hline
\end{tabular}

1 PDME: phosphatidyl dimethylethanolamine.

2 Figures represent averages of quadruplicate determinations made after l-hr incubation.

${ }^{3}$ The reaction mixture for CDP-choline (cytidine diphosphate choline) incorporation contained $50 \mu$ moles Tris buffer $\mathrm{pH} 8.0$, $10 \mu$ moles $\mathrm{MgCl}_{2}, 5 \mu$ moles reduced glutathione, $0.25 \mathrm{ml} 30 \%$ homogenate of lung tissue (in $0.01 \mathrm{~m}$ Tris, $\mathrm{pH} \mathrm{7.2)} \mathrm{and} 1 \mu \mathrm{mole}$ CDP- $\left(1,2 \cdot{ }^{14} \mathrm{C}\right)$ choline in a final volume of $0.55 \mathrm{ml}$.

4 The reaction mixture with $S$-adenosyl-L-methionine was identical except for adjustment of the reaction mixture to $\mathrm{pH}$ 7.4 before incubation and the use of $1 \mu$ mole $\left({ }^{14} \mathrm{CH}_{3}\right)_{-} S$-adenosylL-methionine as the precursor. Other details and extraction procedures are described in Materials and Methods.

The left lower lobe of one lung from each of two previable fetuses was homogenized in $0.01 \mathrm{M}$ Tris buffer, pH 7.2 [20], for studies of enzymatic activity. The entire right lung of each fetus, was lavaged with $0.9 \%$ saline through the main stem bronchus and the alveolar wash was extracted for analysis as described above.

Lung homogenates were incubated with CDP-(1,2${ }^{14} \mathrm{C}$ ) choline (specific activity $48,000 \mathrm{cpm} / \mu$ mole), syn- thesized according to Kennedy [26], and with $\left({ }^{14} \mathrm{CH}_{3}\right)$ $S$-adenosyl-L-methionine [37] as described previously $[18,20]$.

Reaction mixtures (described in Table I) were incubated for $1 \mathrm{hr}$ at $37^{\circ}$; reactions were stopped with $3 \mathrm{ml}$ absolute ethanol. Lipids were extracted rapidly as described by Kennedy [20, 27] and were passed through microcolumns of DEAE-acetate [16]; lecithin was isolated by TLC [16]. Radioactivity was measured in a Packard Tri-carb scintillation spectrometer [20].

\section{Results}

In all studies, $\alpha$-and $\beta$-carbon fatty acids on phospholipids were quantified separately by GLG. Fatty acids were identified by carbon chain length and by numbers of unsaturated bonds and included 14:0, $16: 0,16: 1,16: 2,18: 0,18: 1,18: 2,18: 5,20: 0,20: 4$, $22: 0,22: 2$, and $23: 0$ (the figure after the colon signifies the number of unsaturated bonds).

There were great similarities in $\alpha$-carbon fatty acid composition of all of the lecithins and PDME examined. The $\alpha$-carbons were distinguished by consistent high percentages of palmitic acid.

The major differences in the lecithins were in the fatty acids esterified on their $\beta$-carbons and, particularly, between their myristic acid (14:0) and palmitic acid $(16: 0)$ components. There were no patterns nor consistent nor even clearly interpretable differences among other fatty acids.

Accordingly, to simplify interpretations and visualization of differences in lecithins in the tables to follow, only the myristic and palmitic acid fractions of the carbon are shown with their standard deviations.

\section{Concentrations of Phospholipid in Lung}

Concentrations of total phospholipids and lecithin in lungs from newborn infants dying of nonpulmonary causes were compared with those from infants dying of hyaline membrane disease (HMD). Similar to those reported by others $[3,8,11]$, lower concentrations both of total phospholipids and of lecithin were found in HMD lungs than in lungs from control infants (Table I). Minimum surface tensions for saline extracts of lung also are shown and indicate loss of surface activity in HMD lungs.

\section{Biosynthesis of Lecithin in Lungs of Previable Fetuses}

Lungs were removed at the moment of death from two fetuses of 18- and 20-week gestation (therapeutic 

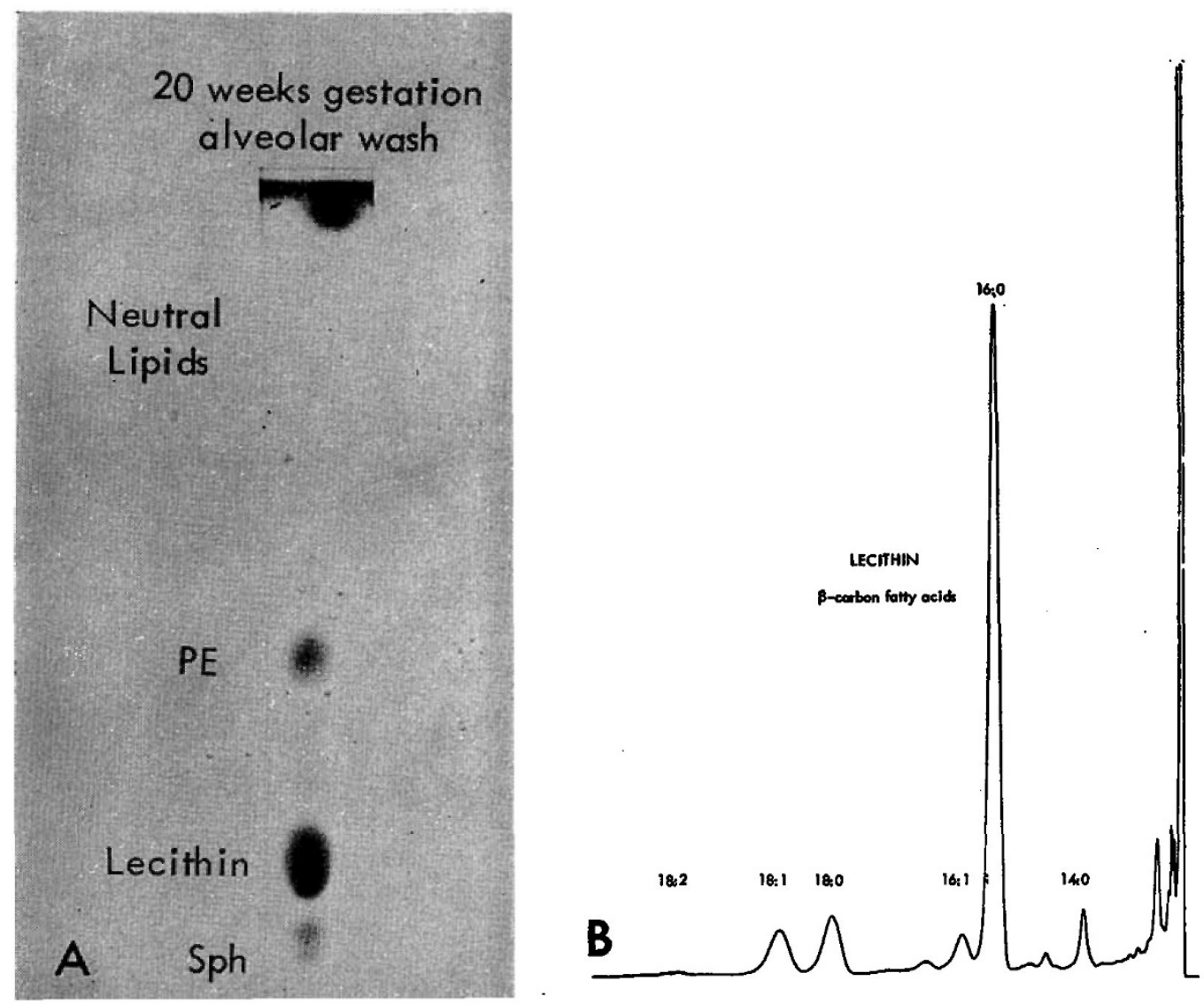

Fig. 1. A: Lipids separated on thin layer chromatography from alveolar wash of 20 -week fetus. No phosphatidyl dimethylethanolamine is seen. B: Gas-liquid chromatography tracing of $\beta$-carbon fatty acids of lecithin which are principally palmitic (16:0). PE: Phosphatidyl ethanolamine. Sph: Sphingomyelin.

hysterotomies). Homogenates of lung from each fetus were incubated either with $\operatorname{CDP}-\left(1,2-{ }^{14} \mathrm{C}\right)$-choline or with $\left({ }^{14} \mathrm{CH}_{3}\right)-S$-adenosyl-L-methionine, precursors of the major pathways for in vitro biosynthesis of lecithin in fetal lung [20].

As shown in Table II, neither fetal lung incorporated more than trace amounts of radioactive methyl groups into lecithin. There was small but definite incorporation of CDP-choline.

Figure $1 A$ is a TLG plate of the nonacidic phospholipids isolated from alveolar wash. Absence of the intermediate in the methylation pathway, dimethylated PE (phosphatidyl dimethylethanolamine, PDME) on TLC, both in alveolar wash and in homogenate of residual lung after wash, also is evidence for lack of methyl transferase enzyme activity [18].

The total amount of acetone-precipitated surface-active lecithin from alveolar wash was very small. As shown in Table III, its principal $\beta$-carbon fatty acid was palmitic acid (see also Fig. $1 B$ ).
Table III. Composition of myristic (14:0) and palmitic (16:0) acids esterified on the $\beta$-carbons of surface-active acetone-precipitated alveolar wash lecithin isolated from two previable human fetuses. Values given in per cent

\begin{tabular}{ccc}
\hline Fatty acid & $\begin{array}{c}\text { 18-week human } \\
\text { fetus }\end{array}$ & $\begin{array}{c}\text { 20-week human } \\
\text { fetus }\end{array}$ \\
\hline $14: 0$ & 12.2 & 7.5 \\
$16: 0$ & 73.9 & 61.3 \\
\hline
\end{tabular}

\section{Comparison of Aspirates and Alveolar Wash}

Lipid compositions and acyl esters of PDME and lecithin in aspirates were compared with those in alveolar wash. Secretions from trachea and pharynx from three adults and five infants without RDS before death and alveolar wash obtained from the same patients after death were examined. Comparisons were considered "valid" because aspirates were obtained close to the time of death and the patients died acutely thus minimizing agonal effects. 


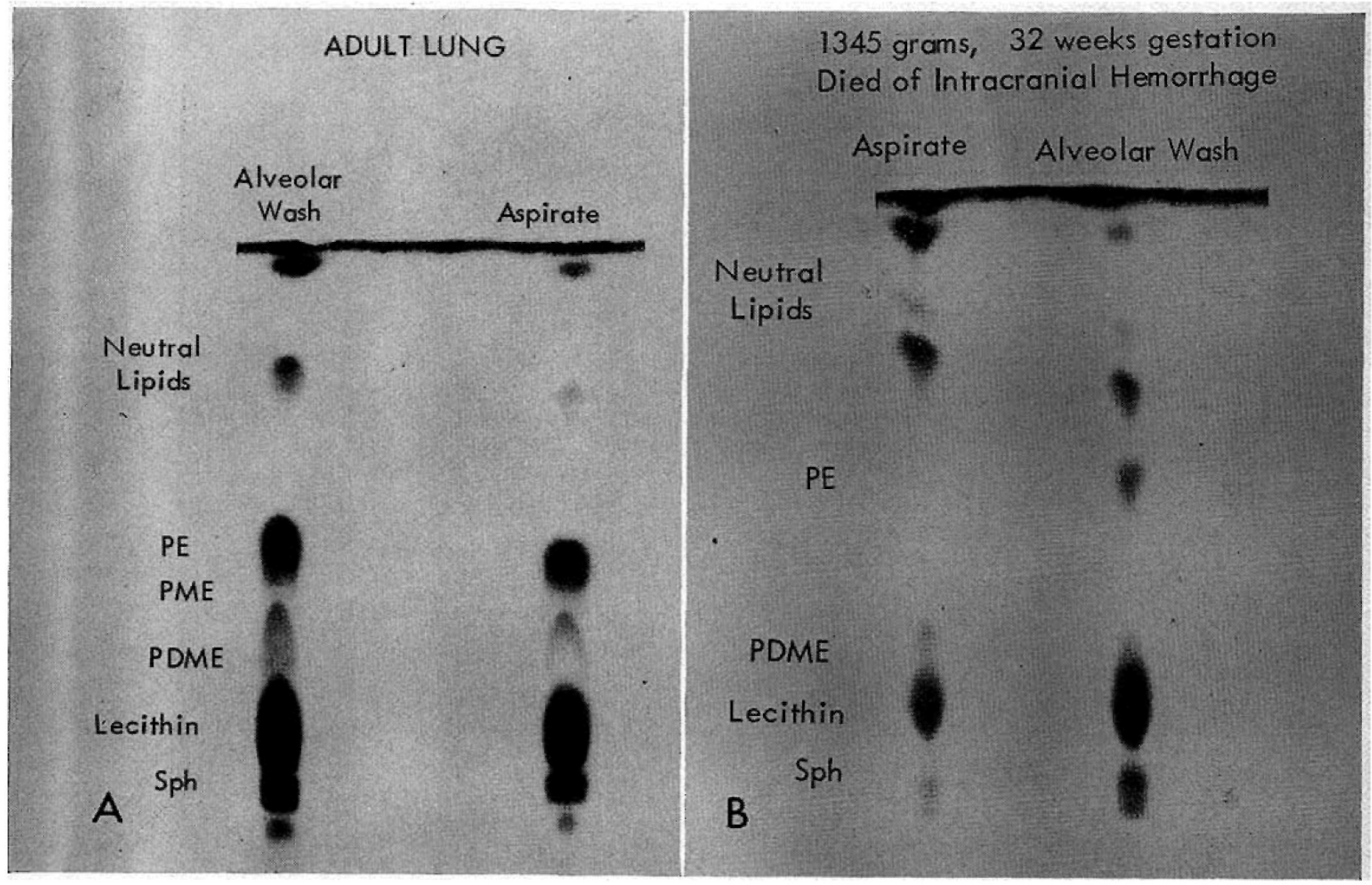

Fig. 2. Qualitative comparison by thin layer chromatography of lipids in alveolar wash with those in tracheal aspirates in $(A)$ adult and $(B)$ newborn infant. Close similarities are seen between alveolar wash and tracheal aspirates and between adult and infant. PE: phosphatidy] ethanolamine. PME: Phosphatidyl methylethanolamine. PDME: Phosphatidyl dimethylethanolamine. Sph: Sphingomyelin.

Two adults had cerebral vascular accidents and tracheostomies (male: 68 years; female: 56 years) and one had an acute surgical death (female: 38 years) from whom, before death, the anesthesiologist had collected tracheal aspirates as part of a study on the effects of inhalation anesthetics on pulmonary phospholipids.

Phospholipid composition in tracheal aspirates and alveolar lavage essentially were identical for each patient. A decreased proportion of PE was found in some samples of aspirates as compared with $\mathrm{PE}$ in alveolar wash (see Fig. 2B). These were found in aspirates allowed to sit at room temperature for I-2 hr, possibly representing continuing methylation of $\mathrm{PE}$. The component fatty acids of lecithin in both aspirates and lavage resembled each other closely. Similar comparisons were true for PDME. Table IV shows representative percentages by GLC of $\beta$-carbon fatty acids of lecithin and PDME isolated from aspirates and alveolar wash from an adult (38-year-old female, Fig. 2A).
The five infants died of causes other than RDS: three died acutely with intracranial hemorrhage in the first $48 \mathrm{hr}$ (1345 g, 32-week gestation; $980 \mathrm{~g}$, 29-week gestation; and $1580 \mathrm{~g}$, 31-week gestation); of the two term infants, one was anencephalic and one had multiple malformations. Figure $2 B$ is the TLC comparison of phospholipids in aspirate and alveolar wash of the 1345-g infant. Proportions of nonacidic phospholipids were very similar. The similarity between fatty acid compositions on surface-active acetone-precipitated lecithin in both aspirates and alveolar lavage and on PDME in both aspirates and alveolar wash is shown in Table IV.

\section{Comparison of Phospholipids in Saliva and Aspirates}

Several collections of saliva from both infants and adults were extracted and examined. All lacked both PDME and surface-active lecithin. Fatty acids of salivary lecithin differed markedly from those of lecithin 
in aspirates, principally in a lesser percentage of saturated fatty acids on the $\beta$-carbon. Newborn infants produce extremely meager saliva in the first several days of life, so that the saliva studied came from 4-6week-old infants.

\section{Occurrence and Structure of Phosphatidyl Dimethyle- thanolamine (PDME)}

Phosphatidyl dimethylethanolamine was found in aspirates as early as 22-24-week gestation and thereafter in tracheal aspirates and alveolar wash of nearly all breathing infants without RDS. Exceptions were infants with unusual diseases such as those with Potter's syndrome and hypoplastic lungs, and in infants severely acidotic or hypothermic after delivery (Fig. 10, $A$ and $B$ ).

The acyl composition is remarkably constant, particularly the $\beta$-carbon fatty acids of surface-active acetone-precipitated PDME, shown in Table V, predominantly myristic (14:0) acid. Palmitic acid (16:0) was the prinicipal fatty acid on the $\alpha$-carbon. This characterized the acyl structure of acetone-precipitated human PDME as $\alpha$-palmitic/ $\beta$-myristic acid, similar to that from adult rabbit alveolar wash [9].

Table IV. Composition of myristic $(14: 0)$ and palmitic $(16: 0)$ acids esterified on the $\beta$-carbons of acetone-precipitated PDME and lecithin. ${ }^{1}$ Values given in per cent

\begin{tabular}{|c|c|c|c|c|c|c|c|c|}
\hline & \multicolumn{4}{|c|}{ Adult ${ }^{2}$} & \multicolumn{4}{|c|}{ Infant $t^{3}$} \\
\hline & \multicolumn{2}{|c|}{ PDME } & \multicolumn{2}{|c|}{ Lecithin } & \multicolumn{2}{|c|}{ PDME } & \multicolumn{2}{|c|}{ Lecithin } \\
\hline & $\begin{array}{l}\text { Alve- } \\
\text { olar- } \\
\text { wash }\end{array}$ & $\begin{array}{l}\text { Aspi- } \\
\text { rate }\end{array}$ & $\begin{array}{l}\text { Alve } \\
\text { olar- } \\
\text { wash }\end{array}$ & $\begin{array}{l}\text { Aspi- } \\
\text { rate }\end{array}$ & $\begin{array}{l}\text { Alve- } \\
\text { olar } \\
\text { wash }\end{array}$ & $\begin{array}{l}\text { Aspi- } \\
\text { rate }\end{array}$ & $\begin{array}{c}\text { Alve- } \\
\text { olar } \\
\text { wash }\end{array}$ & $\begin{array}{c}\text { Aspi- } \\
\text { rate }\end{array}$ \\
\hline $14: 0$ & 66.5 & 63.0 & 39.6 & 40.1 & 84.5 & 80.1 & 64.2 & 68.4 \\
\hline $16: 0$ & 14.2 & 16.2 & 45.3 & 44.5 & 4.7 & 5.4 & 24.2 & 22.0 \\
\hline
\end{tabular}

PDME: phosphatidyl dimethylethanolamine. This table compares those myristic and palmitic acids isolated from alveolar wash with those isolated from tracheal aspirates. Characteristic patients are compared as described in text. Thirty-eight-year-old female, acute surgical death.

$1345 \mathrm{~g}, 32$-week gestation, died age $27 \mathrm{hr}$ of intracranial bleeding.

\section{Acetone-soluble and Acetone-precipitated Lipid Frac-} tions in Aspirates

Figures $3 A$ and $4 A$ are representative thin layer chromatograms of lipids in aspirates from infants $\mathrm{I} \mathrm{hr}$ of age: one $1030 \mathrm{~g}$, 33-week gestation; the other $2000 \mathrm{~g}$, 37-week gestation). The extracts were separated into acetone-soluble and acetone-precipitated (surface-active [19]) fractions. In both apparently normal infants, the acetone-precipitated lecithin had a preponderance of myristic acid on the $\beta$-carbon similar to those shown in Table VI.

Greater amounts of neutral lipids (e.g., free fatty acids, cholesterol and esters, and glycerides), principally acetone-soluble, appeared in aspirates from term infants than from premature infants. Phosphatidyl dimethylethanolmine (PDME), almost all acetone-precipitable, comprised a much greater proportion of nonacidic phospholipids (lecithin, sphingomyelin, PDME, PME, PE) in premature infants than in term infants.

\section{Fatty Acid Esters of Lecithin in Aspirates from Infants without RDS}

The $\alpha$ - and $\beta$-carbon acyl esters of acetone-precipitated lecithin in aspirates at $1 \mathrm{hr}$ of life from stabilized clinically normal infants of various gestational ages were examined. Compositions of lecithin fatty acids from infants shown in Table VI resemble closely those of PDME (see Table V), in a predominance of $\beta$-carbon myristic acid (14:0).

The fatty acid compositions of surface-active lecithin varied both with gestational maturity and with age after birth, principally in increasing percentages with time of $\beta$-carbon palmitic acid. The fatty acid composition of PDME did not change regardless of gestational or postnatal age.

By $12 \mathrm{hr}$ of age or earlier, surface-active lecithin in

Table $V$. Composition of the $\beta$-carbon fatty acids in acetone-precipitated PDME ${ }^{1}$ isolated from aspirates and alveolar wash of infants of varying gestational ages. Values given in per cent ${ }^{2}$

\begin{tabular}{|c|c|c|c|c|c|c|c|c|}
\hline \multirow{2}{*}{\multicolumn{4}{|c|}{ Alveolar wash ${ }^{3}$}} & \multicolumn{5}{|c|}{ Aspirates from trachea or oropharynx, or both } \\
\hline & & & & \multicolumn{3}{|c|}{ Vaginal delivery } & \multicolumn{2}{|c|}{ Cesarean section } \\
\hline $\begin{array}{l}\text { Fatty } \\
\text { acid }\end{array}$ & $\begin{array}{c}750-1485 \mathrm{~g} \\
22-28-\mathrm{wk} \\
\text { gestation, } \\
6 \text { infants }\end{array}$ & $\begin{array}{l}1550-2795 \mathrm{~g} \\
29-35-\mathrm{wk} \\
\text { gestation, } \\
5 \text { infants }\end{array}$ & $\begin{array}{c}3100-4850 \mathrm{~g} \\
38-42-\mathrm{wk} \\
\text { gestation, } \\
5 \text { infants }\end{array}$ & $\begin{array}{l}1090-1500 \mathrm{~g} \\
25-30-\mathrm{wk} \\
\text { gestation, } \\
5 \text { infants }\end{array}$ & $\begin{array}{l}1680-2880 \mathrm{~g} \\
32-35-\mathrm{wk} \\
\text { gestation, } \\
5 \text { infants }\end{array}$ & $\begin{array}{c}2950-3800 \mathrm{~g} \\
37-41-w \mathrm{k} \\
\text { gestation, } \\
5 \text { infants }\end{array}$ & $\begin{array}{c}1495-2010 \mathrm{~g} \\
30-35 \text {-wk } \\
\text { gestation, } \\
5 \text { infants }\end{array}$ & $\begin{array}{l}2910-3660 \mathrm{~g} \\
37-43-\mathrm{wk} \\
\text { gestation, } \\
5 \text { infants }\end{array}$ \\
\hline $14: 0$ & $79.2 \pm 3.3$ & $68.2 \pm 2.9$ & $72.7 \pm 2.4$ & $82.9 \pm 4.2$ & $71.5 \pm 5.7$ & $68.0 \pm 3.9$ & $71.9 \pm 4.7$ & $64.0 \pm 3.4$ \\
\hline $16: 0$ & $6.0 \pm 1.2$ & $6.0 \pm 0.4$ & $12.0 \pm 1.1$ & $7.2 \pm 1.8$ & $12.2 \pm 2.6$ & $12.0 \pm 1.1$ & $10.4 \pm 3.1$ & $16.1 \pm 1.3$ \\
\hline
\end{tabular}

1 PDME: phosphatidyl dimethylethanolamine.

Mean $\pm \mathrm{SD}$.

All infants died from nonrespiratory causes. 

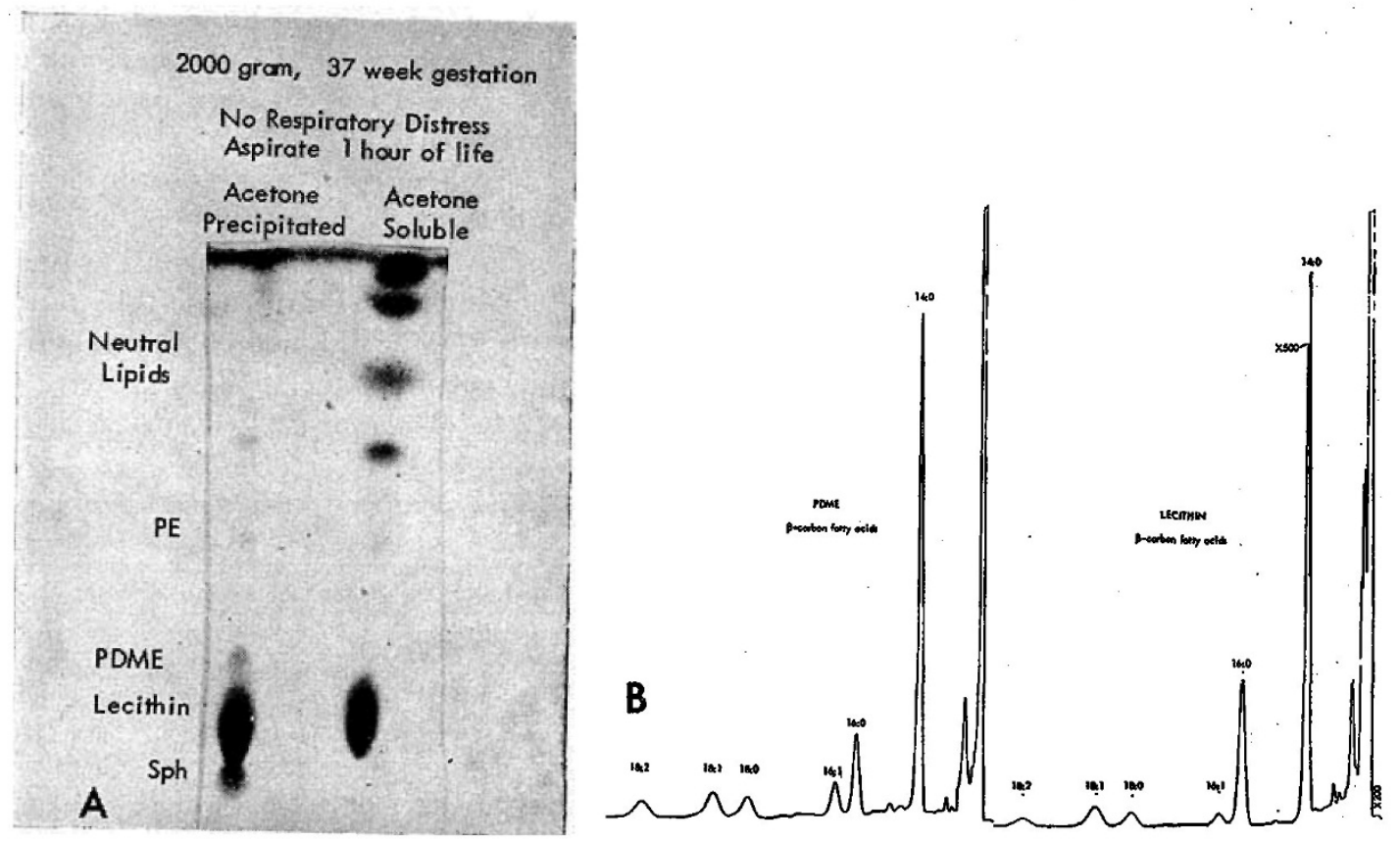

Fig. 3. Aspirates from 1030-g, 33-wk gestation infant with no RDS. A: Thin layer chromatography of acetone-precipitated (Ppt) and soluble $(\mathrm{Sol})$ fractions of lipids. B: Gas-liquid chromatography of fatty acids on the $\beta$-carbons of the PDME and lecithin shown in $A$. Both PDME and lecithin show preponderance of myristic acid (14:0) and little palmitic acid (16:0). Note the close resemblance of the PDME and lecithin fatty acid patterns.
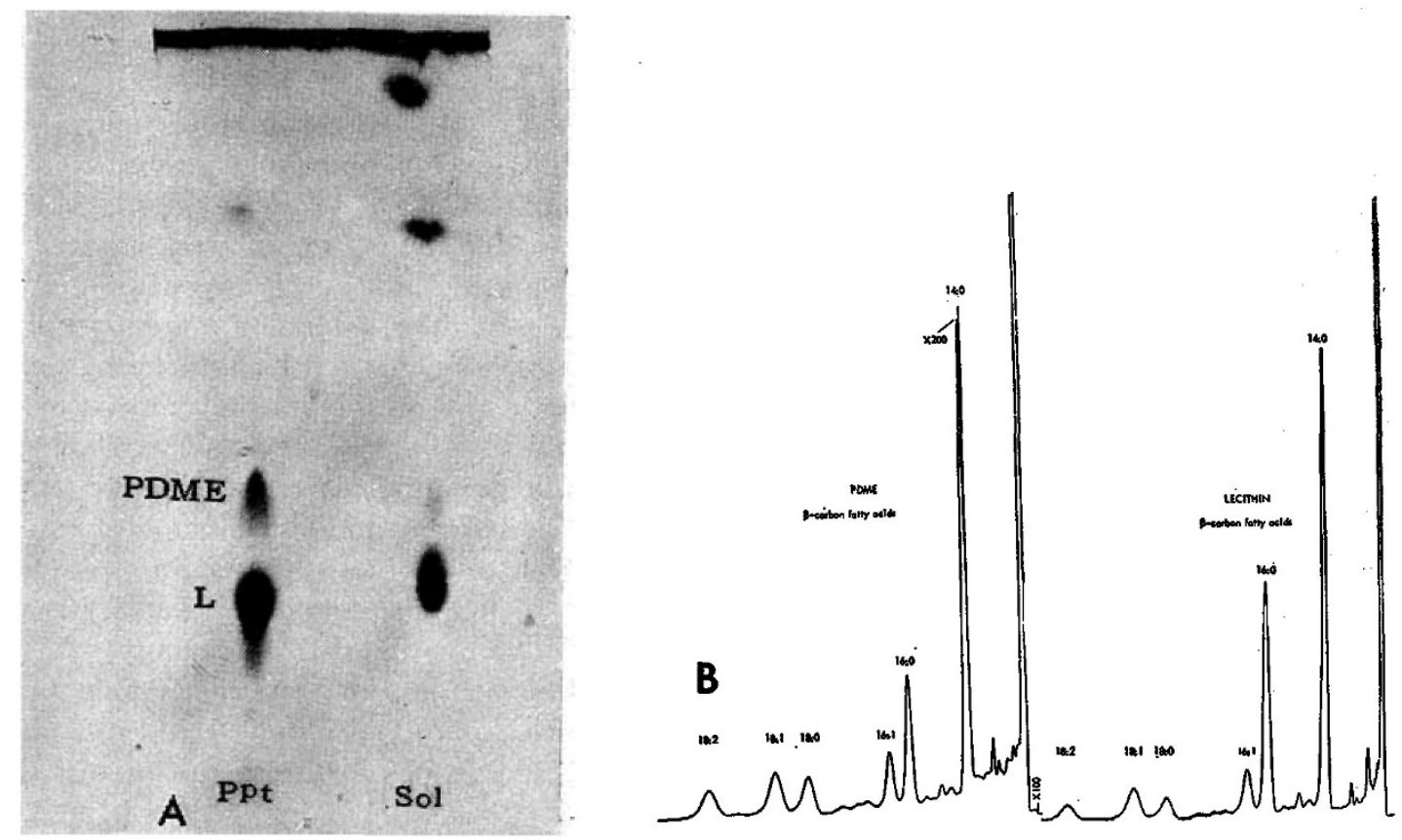

Fig. 4. Aspirates from normal full term infant, $2000 \mathrm{~g}, 37-$ wk gestation without RDS. A: Thin layer chromatography of acetone-precipitated and soluble fractions. $B$ : The fatty acids on the $\beta$-carbons of the PDME and lecithin isolated from tracheal effluent showing pre: ponderant myristic acid (14:0) in PDME and lecithin, but with a larger palmitic acid (16:0) component than in the 1030-g infant of Figure 3. 
aspirates from almost every normal term infant showed similar percentages of palmitic and myristic acids on the $\beta$-carbon. Some infants were born with similar proportions of the two fatty acids, which did not change over the next $12 \mathrm{hr}$ (Table VI).

Generally, infants of less than 36-37 gestational weeks exhibited these changes much later, with few exceptions. In normal infants without RDS, between $33-37$-week gestation, the proportions of $\beta$-carbon palmitic acid on acetone-precipitated lecithin generally were increased by $24 \mathrm{hr}$.

Table VI. Composition of myristic (14:0) and palmitic (16:0) acids on $\beta$-carbons of acetone-precipitated lecithin in aspirates from normal infants of different gestational ages. Values given in per cent ${ }^{1}$

\begin{tabular}{lrrr}
\hline Fatty acid & $\begin{array}{c}1100-1560 \mathrm{~g}, \\
30-33-\mathrm{wk}, \\
\text { gestation, } \\
5 \text { infants }\end{array}$ & $\begin{array}{c}1842-2590 \mathrm{~g}, \\
34-36-\mathrm{wk}, \\
\text { gestation, } \\
5 \text { infants }\end{array}$ & $\begin{array}{c}2680-4250 \mathrm{~g}, \\
38-42-\mathrm{wk} \\
\text { gestation, } \\
12 \text { infants }\end{array}$ \\
\hline $\begin{array}{l}1 \mathrm{hr} \text { of life } \\
14: 0\end{array}$ & $80.2 \pm 4.1$ & $70.0 \pm 6.2$ & $46.1 \pm 3.9$ \\
$16: 0$ & $7.7 \pm 2.9$ & $12.9 \pm 3.3$ & $40.3 \pm 4.1$ \\
12 hrs of life & & & \\
$14: 0$ & $69.4 \pm 6.5$ & $50.1 \pm 5.9$ & $44.8 \pm 7.9$ \\
$16: 0$ & $19.2 \pm 4.2$ & $32.4 \pm 5.1$ & $39.4 \pm 4.1$ \\
\hline
\end{tabular}

${ }^{1}$ Mean \pm SD.
PDME and Lecithin in Aspirates and Alveolar Wash from Infants with RDS

Figures 5 and 6 are representative TLC analyses of aspirates from infants with RDS. With significant RDS, PDME disappeared. With worsening or fulminant RDS (Fig. 6) there also was disappearance of lecithin. This did not reappear and the infant died. Adequate sampling is evidenced by the presence of neutral lipids on chromatograms. With recovery (Fig. 5) there was return of PDME and increase of lecithins in aspirates.

Representative TLG analyses of the alveolar washes of infants who died of RDS (Fig. 7) showed lack of PDME.

On GLC, palmitic acid was the principal $\beta$-carbon fatty acid of acetone-precipitated lecithin from aspirates and alveolar wash of infants dying of RDS (Table VII). The lack of $\beta$-carbon myristic acid coincided with absence of PDME. The lecithin $\alpha$ - and $\beta$ carbon fatty acids of an infant with fatal RDS followed serially are shown in Table VII.

Table VII also shows representative serial analyses of lecithin fatty acids in aspirate from an infant with RDS who recovered. Characteristic of RDS was the marked drop in $\beta$-carbon myristic acid (14:0) coinciding with loss of PDME in the aspirate. With improve-

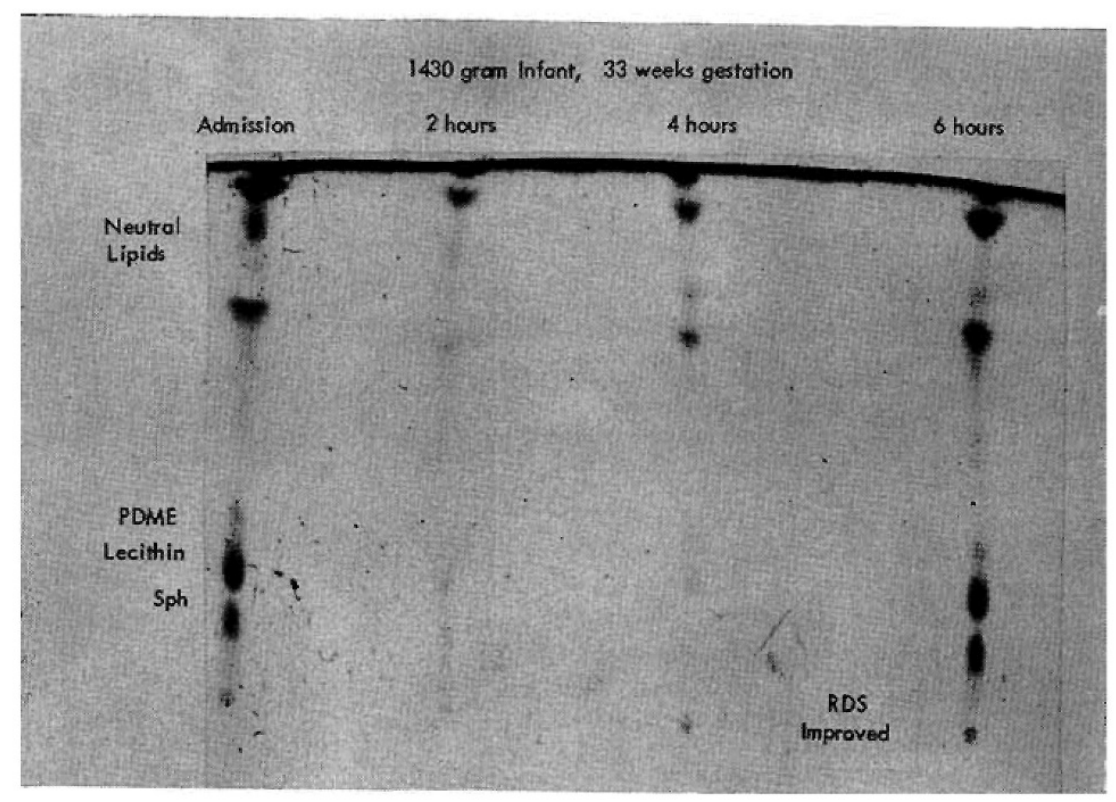

Fig. 5. Thin layer chromatography showing sequential changes in lipids extracted from tracheal aspirates of an infant with RDS who recovered. Phosphatidyl dimethylethanolamine (PDME) and also lecithin first disappear as condition worsens and then reappear with improvement. Cf Figure 6. 
ment, PDME reappeared and the proportion of myristic acid in $\beta$-carbon of lecithin increased.

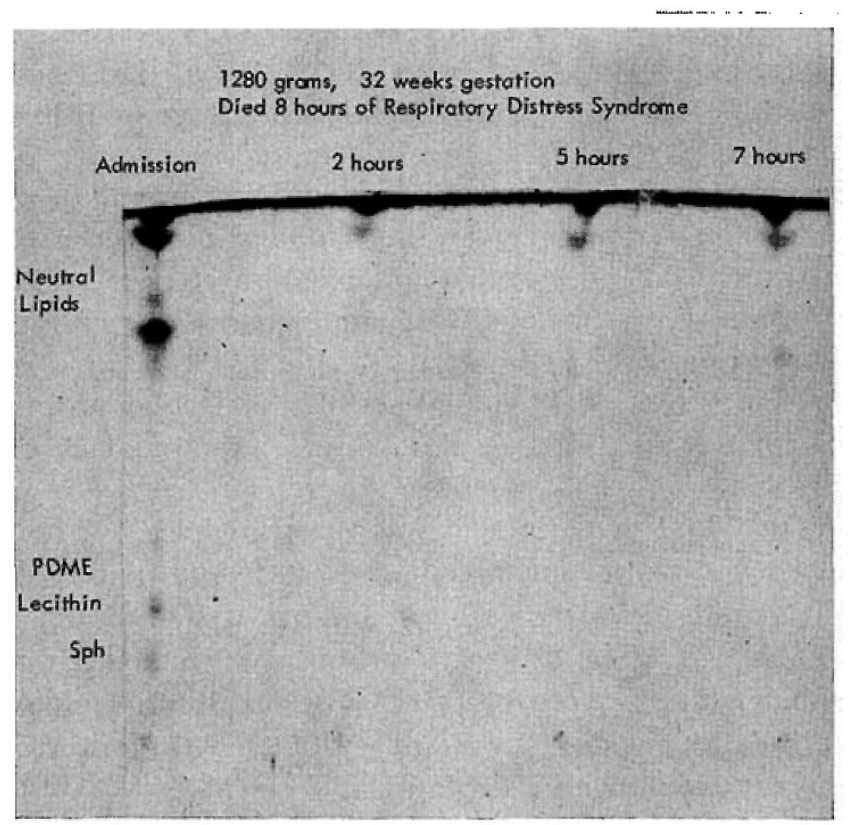

Fig. 6. Thin layer chromatography showing sequential changes in lipids extracted from tracheal aspirates of an infant with fulminant RDS who died after $8 \mathrm{hr}$ of disease with early hyaline membranes. Phosphatidyl dimethylethanolamine (PDME) and lecithin disappear with worsening disease. The sample is valid, with neutral lipids used as reference.

2100 grams, 35 weeks gestation Died of Respiratory Distress Syndrome Non-acidic phospholipids from alveolar wash

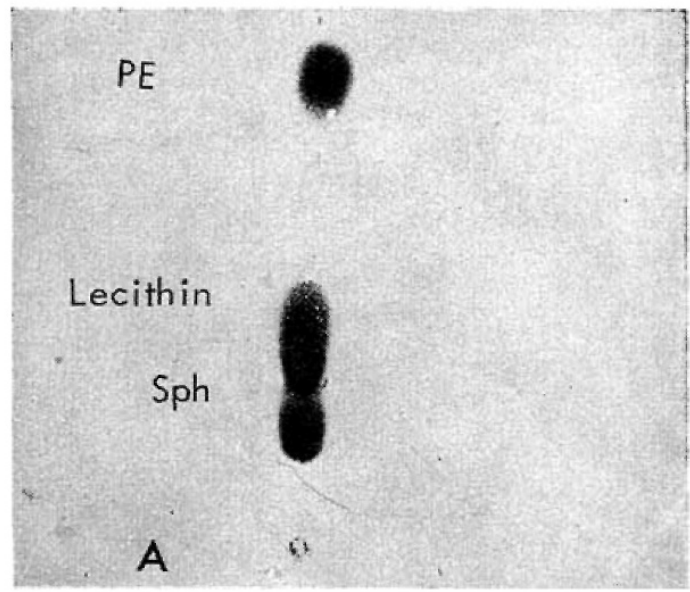

B

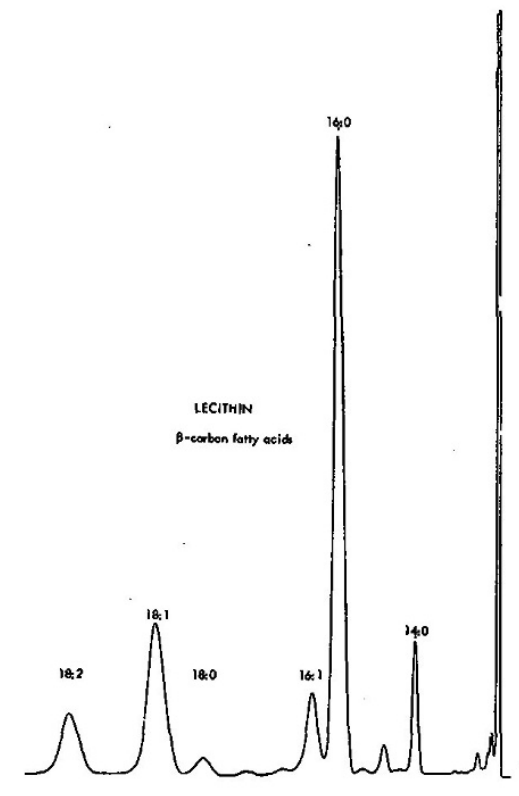

Fig. 7. Alveolar wash from a 2100-g, 35-wk gestation infant dying of RDS. A: Distribution on thin layer chromatography of nonacidis phospholipids. Note absence of PDME. B: Gas-liquid chromatography of $\beta$-carbon fatty acids of the lecithin showing predominance $\mathrm{c}$ palmitic acid (16:0). 
Table VII. Composition of the $\beta$-carbon fatty acids in acetone-precipitated lecithin in aspirates of babies with RDS. ${ }^{1}$ Values given in per cent ${ }^{2}$

\begin{tabular}{|c|c|c|c|c|c|c|c|c|c|c|}
\hline \multirow{3}{*}{$\begin{array}{l}\text { Fatty } \\
\text { acid }\end{array}$} & \multicolumn{10}{|c|}{ Time after birth } \\
\hline & \multirow{2}{*}{$\begin{array}{c}\text { RDS}^{2} \\
6 \mathrm{hr}\end{array}$} & \multicolumn{4}{|c|}{$\underset{\text { recovered }^{3}}{\mathrm{RDS}}$} & \multicolumn{4}{|c|}{$\begin{array}{c}\text { RDS } \\
\text { expired }\end{array}$} & \multirow[b]{2}{*}{$\begin{array}{c}\text { Postmortem } \\
\text { (alveolar wash) }\end{array}$} \\
\hline & & $1 \mathrm{hr}$ & $2 \mathrm{hr}$ & $3 \mathrm{hr}$ & $9 \mathrm{hr}$ & $10 \mathrm{~min}$ & $2 \mathrm{hr}$ & $5 \mathrm{hr}$ & $8 \mathrm{hr}$ & \\
\hline $14: 0$ & $4.2 \pm 2.9$ & 10.7 & 6.6 & 69.4 & 57.6 & 74.3 & 5.9 & 3.1 & 0.7 & 2.1 \\
\hline $16: 0$ & $27.1 \pm 4.3$ & 35.4 & 44.3 & 11.4 & 23.8 & 6.5 & 31.1 & 31.6 & 25.2 & 22.5 \\
\hline
\end{tabular}

1 RDS : respiratory distress syndrome.

212 infants, $1190-2710 \mathrm{~g}, 29-34$-wk gestation; no phosphatidyl dimethylethanolamine; arterial $\mathrm{pH} \leq 7.25, \mathrm{P}_{\mathrm{O}_{2}} 45-50 \mathrm{~mm}$ in $50 \%$ O $\mathrm{P}_{\mathrm{CO}_{2}} 40 \mathrm{~mm}$, x-ray changes, severe respiratory distress. Mean $\pm \mathrm{sD}$.

${ }^{3} 980$-g white male, 31 -wk gestation; depressed at birth, pulse 50, Apgars 2 and 5, body temperature $34^{\circ}$; arterial pH 7.10 at 2 hr; clinically improved by $4 \mathrm{hr}$, "normal" by $8 \mathrm{hr}$.

${ }^{4} 1280$-g white female, 33-wk gestation; at birth Apgars 8 and 9, body temperature $34^{\circ}$; arterial pH 7.10 at $2 \mathrm{hr}, 6.85 \mathrm{at} 8 \mathrm{hr}$; infant expired at $9.5 \mathrm{hr}$.

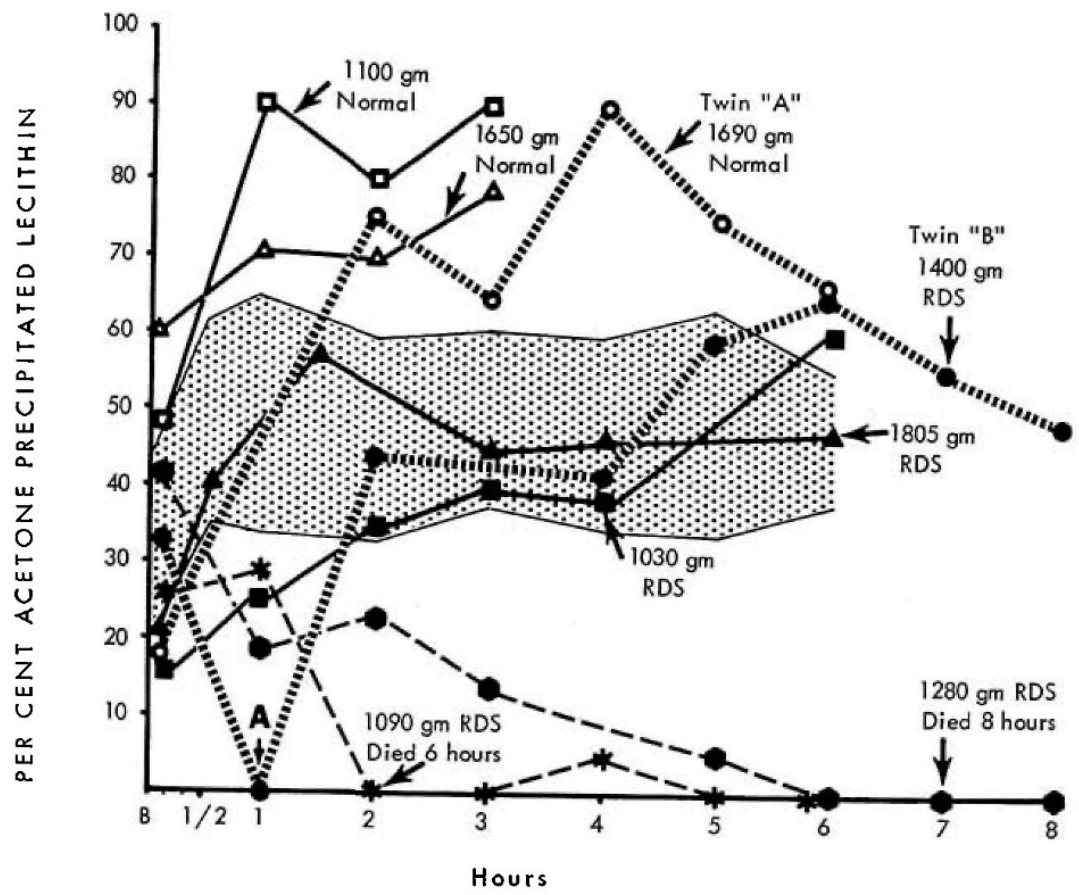

Fig. 8. Changes in percentage of total lecithin fraction provided by acetone-precipitated surface-active lecithin after birth in normal premature infants and in those with RDS. Shaded area represents limits for normal full term infants.

No significant change from a mean of about $50 \%$ was seen after the lst hr, although initial percentages from aspirates at birth were significantly higher (about $30 \%$ ) than those in alveolar wash of rabbits.

\section{Proportions of Acetone-precipitated Lecithin in Aspi- rates from Premature Infants}

Surface-active lecithin formed a variable proportion of total lecithin in aspirates from prematurely born infants. No distinct pattern was established from the onset of breathing, unlike the uniformity in the term infant. Representative percentages of acetone-precipitated lecithin in aspirates from eight premature infants with RDS are shown in Figure 8. Percentages of acetone-precipitated lecithin in aspirates from premature infants, free of RDS regardless of gestational age, were more than in term infants, often above $90 \%$ of the lecithin.

Infants with RDS had lower percentages of acetoneprecipitated lecithin than normal term infants. With recovery from RDS, however, percentages increased to within limits for normal term infants. 


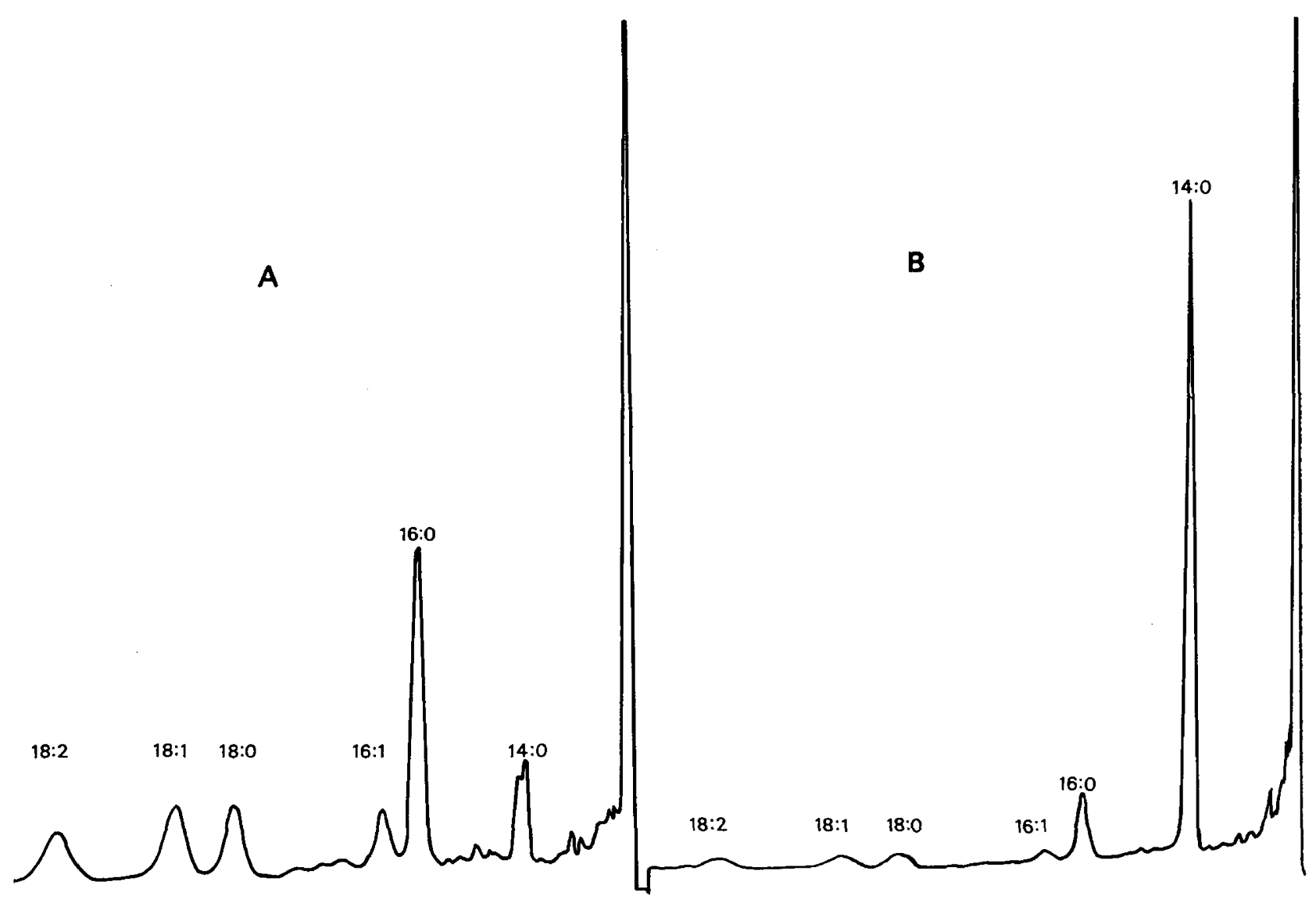

Fig. 9. Male, $1885 \mathrm{~g}$, 33-wk gestation; Apgar scores: 8 at $1 \mathrm{~min}, 9$ at $5 \mathrm{~min}$; body tcmperature $34.5^{\circ}$ at 10 min of age; developed severe RDS. A: Gas-liquid chromatography (GLC) of $\beta$-carbon fatty acids of acetone-precipitated lecithin from tracheal aspirate of infant at 3 $\mathrm{hr}$ of age when $\mathrm{pH}$ was 7.21 and $\mathrm{P}_{\mathrm{CO}_{2}}$ was $62 \mathrm{~mm} \mathrm{Hg}$. Infant was then treated with Tris (THAM). B: GLC of $\beta$-carbon fatty acids of acetone-precipitated lecithin from tracheal aspirates of infant at $12 \mathrm{hr}$ of age when the patient became better and when plasma $\mathrm{pH}$ was 7.30 and $\mathrm{P}_{\mathrm{CO}_{2}}$ was $36 \mathrm{~mm} \mathrm{Hg}$. Six hours later infant was entirely normal clinically ( $\mathrm{pH} 7.36$ ).

In Figure 8, twin $B$ (1400 g, 35-week gestation) developed severe RDS from birth and at $1 \mathrm{hr}(A)$ arterial $\mathrm{pH}$ was 7.09, $\mathrm{P}_{\mathrm{CO}_{2}}$ 70. After intravenous Tris (THAM), $\mathrm{pH}$ rose to $7.20, \mathrm{P}_{\mathrm{CO}_{2}}$ dropped to 51 , and acetone-precipitated lecithin in aspirates increased promptly. There was clinical recovery by $8 \mathrm{hr}$.

In the infant of $1030 \mathrm{~g}$, 31-week gestation, acetoneprecipitated lecithin increased steadily despite RDS from delivery. Initial arterial $\mathrm{pH}$ was 7.22 and $\mathrm{P}_{\mathrm{CO}_{2}}$ was 40 . The $\mathrm{pH}$ corrected spontaneously (only glucose was given intravenously), with recovery clinically by 5 hr.

Changes in lecithin in two representative infants with fulminant RDS are shown. There was rapid total disappearance of surface-active lecithin in their aspirates. That this was not due to poor yield of samples was shown by recovery of some nonsurface-active lecithin until shortly before death and the presence of usual amounts of neutral lipids found in aspirates (compare also Figs. 5 and 6).

Of particular significance, nearly all infants developing RDS had either intrauterine acidosis at birth (usually with a low Apgar score) or hypothermia (e.g., twin $A$ in Figure 8 ), arriving in the nursery at less than $35^{\circ}$. The two "normal" premature infants in Figure 12 (1100 g, 32-week gestation; $1650 \mathrm{~g}$, 34-week gestation) did not develop RDS. They were not cooled, leaving delivery with identical rectal temperatures of $36^{\circ}$. Figure 9 shows GLC tracings of $\beta$-carbon fatty acids of lecithin during RDS and recovery.

Quantification of concentrations of lecithin in single aspirates technically was difficult owing to problems in achieving constant volume of aspirates. The range of variation of concentration from patient to patient per aspirate was too great for statistical significance. However, in the individual patient, concentrations varied 


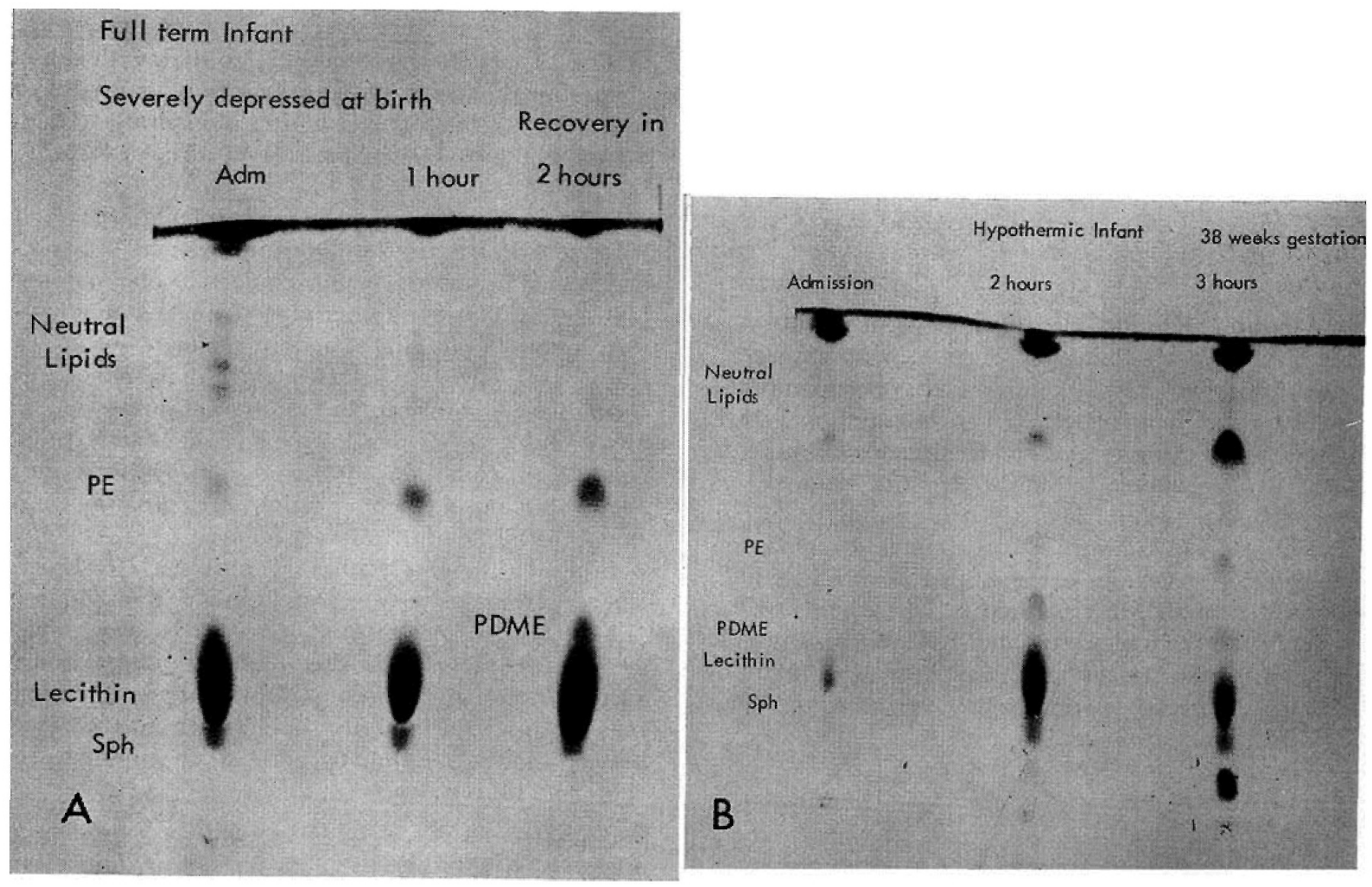

Fig. 10. With acidosis (due to depression during labor), $A$, and hypothermia, $B$, changes similar to those found in premature infants with RDS were found in full term infants who did not get RDS. Phosphatidyl dimethylethanolamine (PDME) disappeared with stress and returned with recovery. (See text for description of changes in $\beta$-carbon fatty acids of lecithin with these stresses.) $A d m$ : Age, 20 min.

according to clinical condition, acetone-precipitated lecithin increasing significantly when RDS improved clinically.

\section{Effects of Acidosis (Depression) on Lecithin in the Full Term Infant}

Figure $10 \mathrm{~A}$ and Table VIII show typical findings with hypoxia acidosis in a term infant $(2970 \mathrm{~g}, 39$-week gestation). He was delivered by emergency section for abruptio placentae, and was limp and apneic at birth (Apgar scores of $\mathrm{l}$ and 3). He was intubated and resuscitated. Arterial pH at $20 \mathrm{~min}$ (labeled $A d m$ ) was 6.80 . Tris buffer was given intravenously. At $1 \mathrm{hr}$ of age, arterial $\mathrm{pH}$ was 7.10 and by $1.5 \mathrm{hr}$ it was 7.25 . At $2 \mathrm{hr}$ of age the infant was improved, pH was 7.32, and he recovered completely. At no time did he have clinical respiratory distress.

Aspirates on admission and $1 \mathrm{hr}$ of age contained no PDME (see Fig. 10A). However, large amounts of leci-
Table VIII. Representative ${ }^{1}$ composition of the $\beta$-carbon fatty acids of acetone-precipitated lecithin isolated from aspirates of full term infants stressed by hypothermia and acidosis. Values given in per cent

\begin{tabular}{|c|c|c|c|c|c|c|}
\hline \multirow{3}{*}{$\begin{array}{l}\text { Fatty } \\
\text { acid }\end{array}$} & \multicolumn{6}{|c|}{ Time after birth } \\
\hline & \multicolumn{3}{|c|}{ Acidosis $^{2}$} & \multicolumn{3}{|c|}{ Hypothermia ${ }^{3}$} \\
\hline & $20 \mathrm{~min}$ & $1 \mathrm{hr}$ & $2 \mathrm{hr}$ & $10 \mathrm{~min}$ & $2 \mathrm{hr}$ & $4 \mathrm{hr}$ \\
\hline $14: 0$ & 51.6 & 9.1 & 46.2 & 46.3 & 13.6 & 41.8 \\
\hline $16: 0$ & 19.4 & 48.2 & 19.3 & 18.3 & 33.9 & 10.5 \\
\hline
\end{tabular}

${ }_{1}$ Patterns in 10 infants with acidosis at birth and subsequent improvement, and in 10 infants with severe hypothermia and subsequent improvement were identical to those of the 2 cases presented. Because there were differences in timing of samples, means and standard deviations are not shown.

2 Full term, 2970 g, 39-wk gestation, emergency section; Apgars 1 and 3; arterial pH 6.80 at $20 \mathrm{~min}$, corrected by $2 \mathrm{hr}$.

${ }^{3}$ Full term, $3400 \mathrm{~g}, 40$-wk gestation; rectal temperature $34^{\circ}$ at 2 hr, $37^{\circ}$ by $4 \mathrm{hr}$. 
thin were present. The $\beta$-carbon fatty acids on acetone-precipitated lecithin at admission primarily were palmitic, as they also were at $\mathrm{l} \mathrm{hr}$. The aspirates on recovery contained significant amounts of PDME and the principal $\beta$-carbon fatty acid on surface-active lecithin at recovery was myristic acid.

\section{Effect of Hypothermia on Lecithin in the Full Term Infant}

Aspirates were obtained from 12 term infants who were significantly cold after delivery, with rectal temperatures below $35^{\circ}$ at $2 \mathrm{hr}$ of life. None manifested signs or symptoms of RDS. In their aspirates, PDME either was lacking or was greatly decreased. The fatty acids on acetone-precipitated lecithin showed decreased percentage of myristic acid and increased palmitic acid. Warming infants (rectal temperatures above $35.5-36.0^{\circ}$ ) was accompanied in aspirates both by return of PDME and increased $\beta$-carbon myristic acid in the acetone-precipitated lecithin. An example is shown in Figure $10 B$ and Table VIII of an infant of $3400 \mathrm{~g}$, 40-week gestation, whose rectal temperature was $34.2^{\circ}$ at $2 \mathrm{hr}$ of age.

\section{Comparison of Surface Activities of $\beta$-Palmitic versus $\beta$-Myristic Lecithin}

Fifty micrograms each of acetone-precipitated lecithin, isolated from RDS lung and from lung of a prematurely born infant (18 hr of age) who died with hypoplastic left heart syndrome, were compared on a modified Wilhelmy balance $\left(60 \mathrm{~cm}^{2}\right)$. This was cycled for $24 \mathrm{hr}$ at room temperature and tensions were recorded.

The lecithin from RDS lung predominantly had $\alpha$ palmitic/ $\beta$-palmitic acid esters, that for non-RDS lung had $\alpha$-palmitic/ $\beta$-myristic. The lowest surface tension recorded by $\alpha$-palmitic/ $\beta$-palmitic lecithin was 0 dyn/ $\mathrm{cm}$. The hysteresis loop was full and stable for about $24 \mathrm{hr}$. The lowest surface tension by $\alpha$-palmitic/ $\beta$-myristic lecithin was $4 \mathrm{dyn} / \mathrm{cm}$. The hysteresis loop was less full and, after $6 \mathrm{hr}$ of cycling, became unstable. Even after $2 \mathrm{hr}$ of cycling there were deviations from base line.

\section{Discussion}

\section{Physiologic Aspects of Alveolar Stability}

During the first breath of life Karlberg et al. [25] found that high negative intrathoracic pressures preceded expansion of lung with air. On expiration, the lung of the normal term infant retains residual air, up to $40 \%$ of total lung volume [21], so that, with subsequent breaths, inspiratory pressures are much lower than with the first. The retention of expiratory residual air is the functional measure of alveolar stability [2].

Lungs excised from premature infants with and without RDS and from stillborn infants may have normal, less than normal, or inadequate alveolar stability [22, 24-28]. This variability suggests that some premature infants born with relatively adequate surfactant cannot synthesize it at sufficient rates after birth, or, at birth, have diminished or, rarely, no surfactant. In any event, with RDS, the infant's lungs cannot hold residual air, collapsing with expiration. He then must again develop a high inflating pressure, in effect breathing his first breath over and over.

In normal lung, a lecithin-laden lining layer lowers surface tension as the alveolus shrinks with expiration $[12-14,32]$. Absence of this surface-active layer results in negative pressures greater than the normal intrapleural negative pressure [32], whereupon the lung may collapse and fluid may be drawn from the blood vessels, against the osmotic effect of the plasma proteins, and fill the alveoli.

\section{Lung Secretions}

For a variable period after birth, newborn infants are productive of secretions (mucus), often copious, in their posterior oropharynges. These originate in the lung, are brought up into the posterior pharynx, and are swallowed, a process beginning in fetal life [1, 17]. Tracheal aspirates from dying adults and infants were compared with the alveolar wash from their lungs after death. The phospholipid composition and the fatty acid esters of PDME and lecithin in aspirates essentially were identical to those in alveolar wash. The secretions thus reflect the synthesis of lecithin recoverable by endobronchial lavage [20] from the alveolar spaces. They have enabled serial studies to be done ethically and safely on living infants, providing much information about the biosynthesis and metabolism of the surface-active phospholipids in the human alveolar layer.

\section{Lecithin Storage}

In fetal rabbit lung, storage of surface-active acetone-precipitated lecithin begins in lung parenchyma long before it appears, late in gestation (day 29 of a 
31-day gestation), in the alveolar wash [18-20]. The present studies could not document similar storage in human lung. Human fetuses of 18- and 20-week gestation yielded very small amounts of surface-active lecithin, both in tracheal lavage and in residual lung parenchyma after wash. This is consistent with observations by Gruenwald [22] of occasional lung stability in very small fetuses, and with suggestions by Pattle [32] and Reynolds et al. [33] that surface-active alveolar lining appears in human fetuses of about 21-24 weeks gestation.

\section{Biosynthetic Pathways}

In vivo and in vitro studies [18-20] of the developing rabbit fetus revealed two pathways for de novo biosynthesis of lecithin in lung. Both were documented also in lungs of infants:

CDP-choline $+\mathrm{D}-\alpha, \beta$-diglyceride $\rightarrow$ lecithin

$$
\text { (choline incorporation) }
$$

$S$-adenosyl-L-methionine $\rightarrow \mathrm{CH}_{3}+$

$$
\text { phosphatidylethanolamine (PE) } \rightarrow
$$

phosphatidyl methylethanolamine (PME) +

$\mathrm{CH}_{3} \rightarrow$ phosphatidyl dimethylethanolamine

$$
\begin{aligned}
(\mathrm{PDME})+\mathrm{CH}_{3} & \rightarrow \text { lecithin } \\
& (\text { methylation reaction) }
\end{aligned}
$$

It is possible to estimate each pathway's contribution to the synthesis of surface-active alveolar lecithin by the esterified fatty acids on the $\beta$-carbon $[17-20]$ as shown previously.

\section{Choline Incorporation}

Lungs of human fetuses of 18- and 20-week gestation incorporated in vitro almost no (about $2 \%$ ) radioactive methyl groups into lecithin. There was small but definite in vitro incorporation of $\operatorname{CDP}-\left(1,2^{14} \mathrm{C}\right)$-choline into lecithin. The fatty acids esterified on the acetone-precipitated lecithin from these early lungs were predominantly $\alpha$-palmitic/ $\beta$-palmitic. No PDME was found. This verified finding in the rabbit fetus delivered at 29 days, whose surface-active alveolar wash lecithin at $1 \mathrm{hr}$ of life was labeled $100 \%$ by radioactive precursors [18-20] and $90 \%$ by choline incorporation, was principally $\alpha$-palmitic/ $\beta$-palmitic, and there was no PDME.

\section{Methylation Reaction}

The methylation pathway, virtually noncontributory to alveolar lecithin in the breathing rabbit newborn, is of paramount importance to survival of the prematurely born human, becoming active at least by the 22nd-24th week of gestation.

The rate-limiting step in this pathway is introduction of the first methyl group on PE [20], after which the reaction rapidly goes to completion. The fatty acid esters associated with the methylation pathway may thus be characterized by examining those fatty acids esterified on an intermediate. Because it is relatively abundant, differs from lecithin by only one methyl group, and is surface-active [19, 29], PDME was the intermediate chosen. At birth, aspirates from all normal newborns including prematures contain PDME. The fatty acid esters of surface-active PDME principally are $\alpha$-palmitic/ $\beta$-myristic acid. The almost identical acyl esters of lecithin and PDME in the prematurely born infant indicate that this alveolar lecithin is synthesized largely by methylation of $\mathrm{PE}$.

\section{Assessment of Biosynthesis Pathways}

Presence of PDME and predominantly $\alpha$-palmitic/ $\beta$ myristic acid lecithin indicates synthesis largely through methylation of $\mathrm{PE}$; absence of PDME and lecithin, primarily $\alpha$-palmitic/ $\beta$-palmitic, signifies synthesis largely by CDP-choline incorporation. Presence of PDME and lecithin with $\alpha$-palmitic/ $\beta$-palmitic and myristic acids is a normal change occurring in full term infants in the first few hours after birth and is present in adults, indicating that both pathways are active. The change to both fatty acids on surface-active lecithin may take the premature infant from 12 to 144 hr postbirth.

\section{Differences in Lecithin}

The marginal extrauterine pulmonary adaptation of premature infants, until adequate synthesis of lecithin by CDP-choline incorporation, stems both from less production of lecithin (primarily by methylation in the premature's lung) and differences in the lecithins themselves, in that $\alpha$-palmitic/ $\beta$-palmitic acid lecithin produced by the CDP-choline pathway is more stable on the modified Wilhelmy balance than is the $\alpha$-palmitic/ $\beta$-myristic acid lecithin from the methylation pathway.

\section{Initiation of $R D S$,}

Acetone-precipitated lecithin and PDME in aspirates may decrease or disappear in infants developing 
RDS, accompanied by a change in fatty acids of lecithin, principally to $\alpha$-palmitic/ $\beta$-palmitic. These changes almost always are initiated by hypoxia and acidosis or hypothermia, or both.

\section{Hypothermia}

The most interesting stress associated with RDS is hypothermia from birth. Possibly cold evokes a catecholamine response [10], with constriction of pulmonary vessels and decreased pulmonary blood flow. Possibly catecholamines may compete for methyl groups from methionine, thereby selectively inhibiting methylation of PE. Possibly the acidosis following hypothermia triggers the effects.

There was no critical temperature associated with RDS. Few infants developed symptoms with rectal temperatures above $35^{\circ}$ on admission, whereas premature infants with admission temperatures below $34.5^{\circ}$ developed the most severe RDS. Statistically, such hypothermia for the premature prolonged beyond $2 \mathrm{hr}$ was associated with an especially high mortality.

Aspirates from both full term and prematurely born infants with hypothermia showed decreased lecithin, decreased or absent PDME, and changes in acyl esters of lecithin to $\alpha$-palmitic/ $\beta$-palmitic.

\section{Acidosis}

Low $\mathrm{pH}$ inhibits methylation. Methyl incorporation in vitro by rabbit lung homogenate [20] is nearly completely inhibited below pH 7.2. It also seems to be confirmed clinically in the human during the course of RDS. Coinciding with low arterial $\mathrm{pH}, \mathrm{PDME}$ disappears from aspirates as the infant's condition deteriorates. An increase in $\mathrm{pH}$ toward correction with, e.g., vigorous ventilatory support (or with buffers) is followed by return of PDME.

\section{Changes during RDS}

When RDS improves, PDME reappears, lecithin increases, and proportions of $\beta$-carbon myristic acid increase in acetone-precipitated lecithin in aspirates. In infants dying of RDS, there is no return of PDME, lecithin remains scant, and its fatty acid esters are $\alpha$ palmitic/ $\beta$-palmitic lecithin. With this inhibition of methylation, choline incorporation becomes the only pathway by which the infants' lung may synthesize lecithin. When the infants' lungs are too immature (usually less than 36 weeks), choline incorporation may be too ineffectually developed. Progressive alveolar collapse may initate the atelectasis, anoxia, and acidosis so often progressing to death.

\section{Changes with Hypothermia and Acidosis in Full Term Infants}

Hypothermia and hypoxia acidosis affected methylation and produced chemical changes in stressed full term infants similar to those changes in premature infants with RDS. The PDME disappeared and fatty acids on acetone-precipitated lecithin became primarily $\alpha$-palmitic/ $\beta$-palmitic. However, those infants did not develop RDS. Mature newborn infants synthesize surface-active lecithin by both pathways. The choline incorporation pathway seems resistant and able to produce surface-active lecithin in relative abundance, even in the stressed term infant, when there is no evidence of lecithin production by methylation.

\section{Lecithin from the Fetal Lung in Amniotic Fluid}

The preceding observations have been extended by examining phospholipids in amniotic fluid [17]. Although sources other than lung also contribute amniotic fluid phospholipids, lecithin, the major fraction, appears to originate largely from lung. Acyl esters of acetone-precipitated lecithin, isolated from amniotic fluids during gestation, reflected findings almost identical to those described here. Comparison of surface-active lecithin from amniotic fluid showed close resemblance to that from tracheal aspirates.

There was evidence of intrauterine methylation $(\alpha-$ palmitic/ $\beta$-myristic acid lecithin) early in gestation, and, about week 35 of gestation, evidence of synthesis of lecithin also by the CDP-choline incorporation (increasing $\beta$-palmitic acid).

Intrauterine lung maturation is clearly defined by an abrupt rise in the ratio of amniotic fluid lecithin/ sphingomyelin. With gestation, lecithin concentration increases. Until week 34 the lecithin/sphingomyelin ratios hover around 1 ; i.e., about equal concentrations of the two phospholipids. About weeks 35-36, lecithin/sphingomyelin rises sharply after a "surge" of lecithin, when pulmonary maturity is achieved, and, should birth occur, there will be no RDS.

\section{Evolutionary Aspects}

Comparisons with other species show that presently there is no known suitable animal model for the study of RDS, including the commonly studied sheep and rabbit. Neither sheep nor rabbits can be prematures in the same sense that humans and other primates are. Rabbits and sheep develop pulmonary competence late in fetal life coincident with appearance of sufficient surfactant to maintain alveolar stability and to 


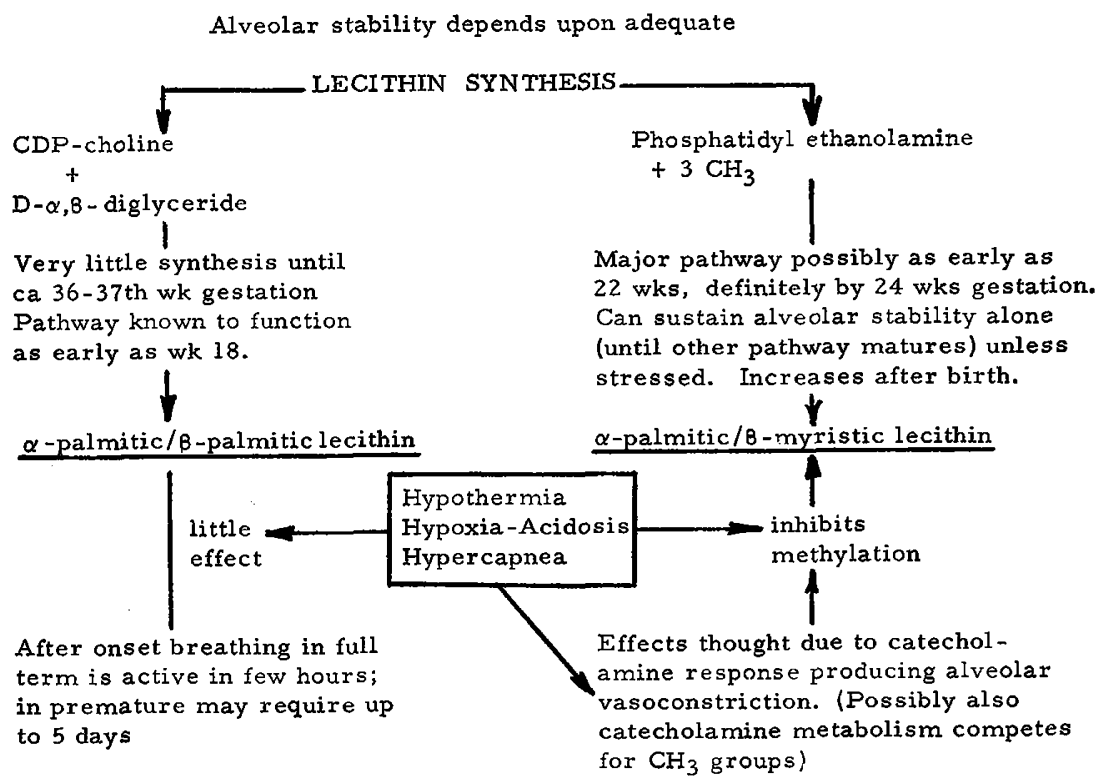

Fig. 11. Scheme of timing of 2 pathways for synthesis of lecithin. Stresses and effects on each pathway are indicated. Initially, the CDPcholine pathway is not affected by conditions such as hypothermia and acidosis.

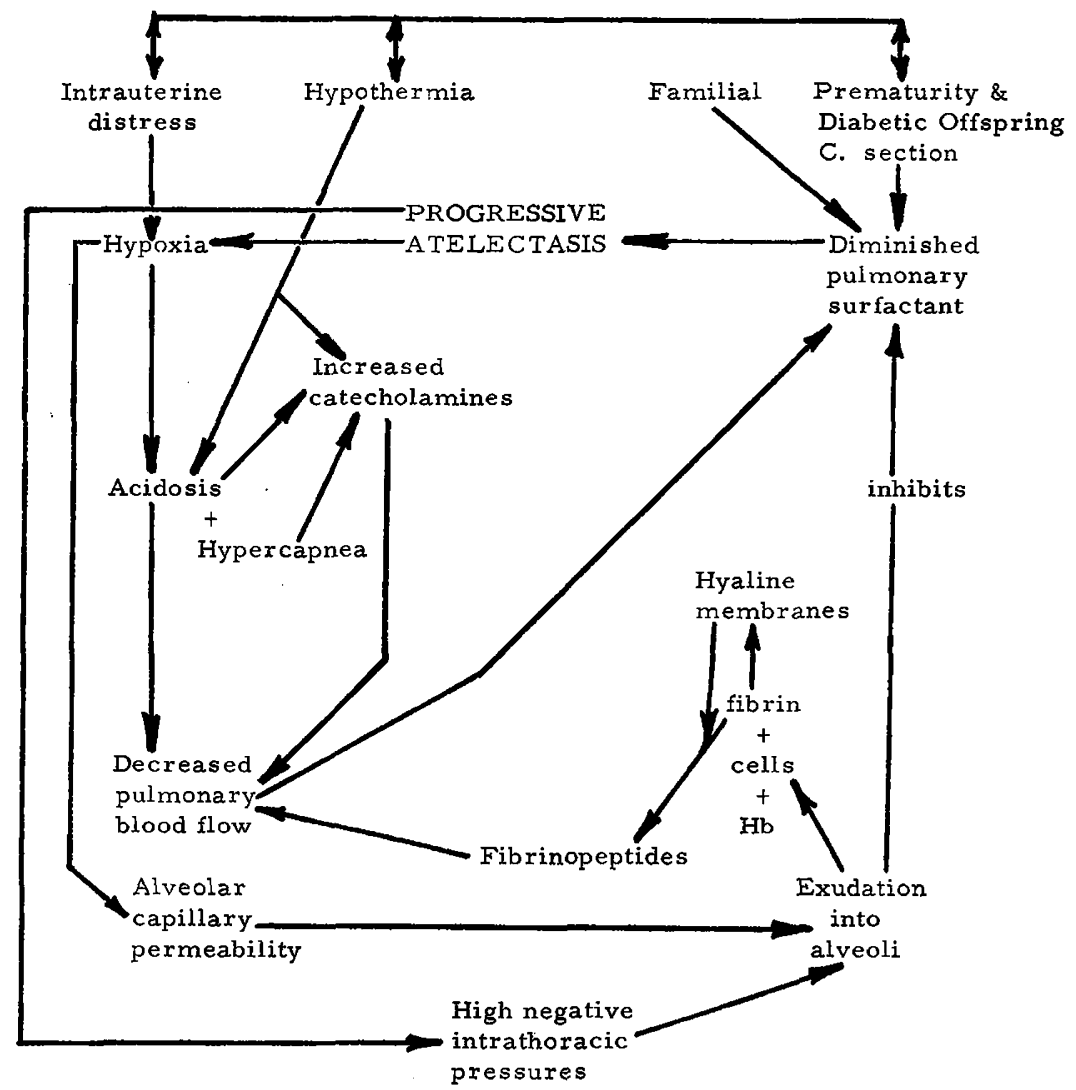

Fig. 12. Probable vicious cycle centered about the progressive atelectasis resulting initially from low levels of pulmonary surfactant. The force set in motion by collapse, hypoxia, and the like, may become cumulatively deflating, resulting in hyaline membranes as shown. 
support life. Rabbit survival is dependent upon surface-active lecithin synthesis by CDP-choline pathway, which becomes significantly active at day $28-29$ of a 31 -day gestation (90-93\% of gestation). Sheep survive around day 127-130 of a 150-day gestation (about $87 \%$ of gestation). In mice, day 18 of a 19-day gestation is the time of appearance of surface activity and of survival [9] (94\% of gestation). In the human, survivors after 24-28-week gestation are not rare $(60-70 \%$ of gestation). This is when the fetus makes alveolar lecithin chiefly by methylation. The "surge" of lecithin in human fetal lung marks maturation of CDP-choline incorporation at about week 36. Similar to other Mammalia, this occurs at $90 \%$ of gestation.

\section{Summary}

The following two figures sum up the findings presented and put them into perspective. Figure 11 diagrams the developmental sequences and influences associated with normal and abnormal lecithin production.

Figure 12 is a diagram of the interrelationships of atelectasis in RDS and HMD. Caused by inability to maintain residual air in his alveoli, the end of expiration with each breath is marked by alveolar collapse. The resultant high intrathoracic pressures become part of a vicious cycle of events which include exudation of plasma into alveolar spaces, hypoxia, acidosis, decreased pulmonary blood flow, endothelial damage and extravasation, epithelial necrosis, clotting [4, 5], and obliteration of alveoli with some dilatation of terminal bronchiolar and alveolar duct areas.

Thus the respiratory distress syndrome is not a "disease," but a consequence of development. It should be called not idiopathic RDS, but more appropriately developmental RDS.

\section{References and Notes}

1. Adams, F. H., Desilets, D. T., AND Towers, B.: Control of flow of fetal lung fluid at the laryngeal outlet. Resp. Physiol., 2: 302 (1967).

2. Adams, F. H., and Fujiwara, T.: Surfactant in fetal lamb tracheal fluid. J. Pediat., 63: 537 (1963).

3. Adams, F. H., Fujiwara, T., Emmanouilides, G., and Scudder, A.: Surface properties and lipids from lungs of infants with hyaline membrane disease. J. Pediat., 66: 357 (1965).

4. Ambrus, C. M., Weintraub, D. H., Dunphy, D., Dowd, J. E., Pickren, J. W., Niswander, K. R., And Ambrus, J. L.: Studies on hyaline membrane disease. I. The fibrinolysin system in pathogenesis and therapy. Pediatrics, 32: 10 (1963).

5. Ambrus, C. M., Weintraub, D. H., and Ambrus, J. L.: Studies on hyaline membrane disease. III. Therapeutic trial of urokinase-activated human plasmin. Pediatrics, 38: 231 (1966).

6. Avery, M. E., AND MEAD, J.: Surface properties in relation to atelectasis and hyaline membrane disease. Amer. J. Dis. Child., 97: 517 (1959).

7. Bartletr, G. R.: Phosphorus assay in column chromatography. J. Biol. Chem., 234: 466 (1959).

8. Brumley, G. W., Hodson, W. A., ANd Avery, M. E.: Lung phospholipids and surface tension correlations in infants with and without hyaline membrane disease and in adults. Pediatrics, 40: 13 (1967).

9. Buckingham, S., AND Avery, M. E.: Time of appearance of lung surfactant in the foetal mouse. Nature, 193: 688 (1962).

10. Cheek, D. B., Malinek, M., and Fraillon, J. M.: Plasma adrenaline and noradrenaline in the neonatal period, and infants with respiratory distress syndrome and placental insufficiency. Pediatrics, 31: 374 (1963).

11. Chu, J., Clements, J. A., Cotton, E., Klaus, M. H., Sweet, A. Y., Thomas, M. A., and Tooley, W. H.: The pulmonary hypoperfusion syndrome. Pediatrics, 35: 733 (1965).

12. Clements, J. A.: Surface tension of lung extracts. Proc. Soc. Exp. Biol. Med., 95: 170 (1957).

13. Clements, J. A.: Surface phenomena in relation to pulmonary function (Sixth Bowditch Lecture). Physiologist, 5: 11 (1962).

14. Clements, J. A., Hustead, R. F., Johnson, R. P., and Gribetz, I.: Pulmonary surface tension and alveolar stability. J. Appl. Physiol., 16: 444 (1961).

15. Fujiwara, T., Adams, F. H., and Scudder, A.: Fetal lamb amniotic fluid: relationship of lipid composition to surface tension. J. Pediat., 65: 824 (1964).

16. Gluck, L., Kulovich, M. V., AND Brody, S. J.: Rapid quantitative measurement of lung tissue phospholipids. J. Lipid Res., 7: 570 (1966).

17. Gluck, L., Kulovich, M. V., Borer, R. C., Jr., Brenner, P. H., Anderson, G. G., and Spellacy, W. N.: The diagnosis of the respiratory distress syndrome (RDS) by amniocentesis. Amer. J. Obstet. Gynecol., 109: 440 (1971).

18. Gluck, L., Landowne, R. A., and Kulovich, M. V.: Biochemical development of surface activity in mammalian lung. III. Structural changes in lung lecithin during development of the rabbit fetus and newborn. Pediat. Res., 4: 352 (1970).

19. Gluck, L., Motoyama, E. K., Smits, H. L., ANo Kulovich, M. V.: The biochemical development of surface activity in mammalian lung. I. The surface active phospholipids; the separation and distribution of surface-active lecithin in the lung of the developing rabbit fetus. Pediat. Res., 1: 237 (1967).

20. Gluck, L., Sribney, M., and Kulovich, M. V.: The biochemical development of surface activity in mammalian lung. II. The biosynthesis of phospholipids in the lung of the developing rabbit fetus and newborn. Pediat. Res., 1: 247 (1967).

21. Gribetz, I., Frank, N. R., ANd Avery, M. E.: Static volumepressure relations of excised lungs of infants with hyaline membrane disease, newborn and stillborn infants. J. Clin. Invest., 38: 2168 (1959).

22. Gruenwald, P.: Pulmonary surfactant and stability of aeration in young human fetuses. Pediatrics, $38: 912$ (1966).

23. Gruenwald, P., Johnson, R. P., Hustead, R. F., and ClemENTS, J. A.: Correlation of mechanical properties of infants' lungs with surface activity of extracts. Proc. Soc. Exp. Biol. Med., 109: 369 (1962).

24. Howatt, W. F., Avery, M. E., Humphreys, P. W., Normand, I. C. S., Rein, L., ANd Strang, L. B.: Factors affecting pulmonary surface properties in the foetal lamb. Clin. Sci. 29: 239 (1965).

25. Karlberg, P., Gherry, R. B., Escardó, F. E., AND KöCh, G.: 
Respiratory studies in newborn infants. II. Pulmonary ventilation and mechanics of breathing in the first minutes of life, including the onset of respiration. Acta Paediat. Scand., 51: 121 (1962).

26. KenNedy, E. P.: The synthesis of cytidine diphosphate choline, cytidine diphosphate ethanolamine, and related compounds. J. Biol. Chem., 222: 185 (1956).

27. KENNEDY, E. P.: Phosphoryl choline-glyceride transferase. In: S. P. Colowick and N. O. Kaplan: Methods in Enzymology, Vol. 5, p. 484. (Academic Press, New York, 1962).

28. Kikkawa, Y., Motoyama, E. K., ANd Gluck, L.: Study of the lungs of fetal and newborn rabbits. Amer. J. Pathol. 52: 177 (1968).

29. Morgan, T. E., Finley, T. N., ANd Fialkow, H.: Comparison of the composition and surface activity of "alveolar" and whole lung lipids in the dog. Biochim. Biophys. Acta, 106: 403 (1965).

30. Orzalesi, M. M., Motoyama, E. K., Jacobson, H. N., KikKawa, Y., ReYNolds, E. O. R., AND CooK, C. D.: The development of the lungs of lambs. Pediatrics, 35: 373 (1965).

31. Partle, R. E.: The formation of a lining film by foetal lungs. J. Pathol. Bacteriol., 82: 333 (1961).
32. Patrle, R. E.: Surface lining of lung alveoli. Physiol. Rev., 45: 48 (1965).

33. Reynolds, E. O. R., Roberton, N. R. C., AND Wigglesworth, J. S.: Hyaline membrane disease, respiratory distress, and surfactant deficiency. Pediatrics, 42: 758 (1968).

34. Setnikar, I., Agostoni, E., And Taglietri, A.: The fetal lung, a source of amniotic fluid. Proc. Soc. Exp. Biol. Med., 101: 842 (1949).

35. Informed consent where appropriate was obtained from parents of patients in the study.

36. DEAE-acetate, Eastman Kodak Company, Rochester, N. Y.

37. Tracerlab, Brookline, Mass. Specific activity 200,000 cpm/ $\mu$ mole.

38. Supported by Public Health Service Research Grants nos. HD01299, HD04143, and HD04380; and by Maternal and Child Health funds of the California State Department of Health.

39. Requests for reprints should be addressed to: Lours GLuck, M.D., Department of Pediatrics, University of California, San Diego, School of Medicine, P.O. Box 109, La Jolla, Calif. 92037 (USA).

40. Accepted for publication March 30, 1971. 